\title{
Article \\ Effect of the Heating Rate to Prevent the Generation of Iron Oxides during the Hydrothermal Synthesis of $\mathrm{LiFePO}_{4}$
}

\author{
Francisco Ruiz-Jorge ${ }^{1}\left(\mathbb{D}\right.$, Almudena Benítez ${ }^{2}{ }^{\circledR}$, M. Belén García-Jarana ${ }^{1}{ }^{\circledR}$, Jezabel Sánchez-Oneto ${ }^{1}$, \\ Juan R. Portela ${ }^{1, *}$ and Enrique J. Martínez de la Ossa ${ }^{1}$ (D) \\ 1 Department of Chemical Engineering and Food Technology, Faculty of Sciences, International Excellence \\ Agrifood Campus (CeiA3), University of Cadiz, 11510 Puerto Real, Spain; franciscojavier.ruiz@uca.es (F.R.-J.); \\ belen.garcia@uca.es (M.B.G.-J.); jezabel.sanchez@uca.es (J.S.-O.); \\ enrique.martinezdelaossa@uca.es (E.J.M.d.1.O.) \\ 2 Department of Inorganic Chemistry and Chemical Engineering, University Institute of \\ Nanochemistry (IUNAN), University of Cordoba, 14071 Córdoba, Spain; q62betoa@uco.es \\ * Correspondence: juanramon.portela@uca.es
}

check for updates

Citation: Ruiz-Jorge, F.; Benítez, A.; García-Jarana, M.B.; Sánchez-Oneto, J.; Portela, J.R.; Martínez de la Ossa, E.J. Effect of the Heating Rate to Prevent the Generation of Iron Oxides during the Hydrothermal Synthesis of $\mathrm{LiFePO}_{4}$. Nanomaterials 2021, 11 , 2412. https://doi.org/10.3390/ nano11092412

Academic Editors: Ivan Stoikov and Pavel Padnya

Received: 4 August 2021

Accepted: 14 September 2021

Published: 16 September 2021

Publisher's Note: MDPI stays neutral with regard to jurisdictional claims in published maps and institutional affiliations.

Copyright: (C) 2021 by the authors. Licensee MDPI, Basel, Switzerland. This article is an open access article distributed under the terms and conditions of the Creative Commons Attribution (CC BY) license (https:/ / creativecommons.org/licenses/by/ $4.0 /)$.

\begin{abstract}
Lithium-ion batteries (LIBs) have gained much interest in recent years because of the increasing energy demand and the relentless progression of climate change. About $30 \%$ of the manufacturing cost for LIBs is spent on cathode materials, and its level of development is lower than the negative electrode, separator diaphragm and electrolyte, therefore becoming the "controlling step". Numerous cathodic materials have been employed, $\mathrm{LiFePO}_{4}$ being the most relevant one mainly because of its excellent performance, as well as its rated capacity $\left(170 \mathrm{~mA} \cdot \mathrm{h} \cdot \mathrm{g}^{-1}\right)$ and practical operating voltage ( $3.5 \mathrm{~V}$ vs. $\mathrm{Li}^{+} / \mathrm{Li}$ ). Nevertheless, producing micro and nanoparticles with high purity levels, avoiding the formation of iron oxides, and reducing the operating cost are still some of the aspects still to be improved. In this work, we have applied two heating rates (slow and fast) to the same hydrothermal synthesis process with the main objective of obtaining, without any reducing agents, the purest possible $\mathrm{LiFePO}_{4}$ in the shortest time and with the lowest proportion of magnetite impurities. The reagents initially used were: $\mathrm{FeSO}_{4}, \mathrm{H}_{3} \mathrm{PO}_{4}$, and $\mathrm{LiOH}$, and a crucial phenomenon has been observed in the temperature range between 130 and $150{ }^{\circ} \mathrm{C}$, being verified with various techniques such as XRD and SEM.
\end{abstract}

Keywords: lithium iron phosphate; hydrothermal synthesis; heating rate; morphology; crystallinity and purity

\section{Introduction}

The global and increasing energy demand, and the need to replace the consequential consumption of fossil fuels because of environmental concerns, has generated a growing interest, not only in the development of renewable sources of energy, but also in the design of more advanced energy storage systems such as lithium-ion batteries (LIBs) [1], super capacitors [2], lithium sulfur batteries [3], sodium sulfur batteries [4], and redox flow batteries [5] with improved energy density and cycling performance. Nowadays, LIBs are important energy storage devices because of their high specific energy, low self-discharge, excellent cycle performance, no memory effect, and lesser environmental impact [6]. About $30 \%$ of the manufacturing budget for LIBs is spent on cathode materials, and its level of development is lower than that of the negative electrode, the diaphragm, or the electrolyte. Therefore, it is the "control step" that determines the battery performance in terms of working voltage, energy density, and rate performance [6]. Numerous cathodic materials have been employed, such as $\mathrm{LiMn}_{2} \mathrm{O}, \mathrm{Li}_{3} \mathrm{~V}_{2}\left(\mathrm{PO}_{4}\right)_{3}$, and $\mathrm{LiCoO}_{2}$, but it is $\mathrm{LiFePO}_{4}$ that has become the main one used because of its excellent performance, as well as its high theoretical specific capacity $\left(170 \mathrm{~mA} \cdot \mathrm{h} \cdot \mathrm{g}^{-1}\right)$, practical operating voltage $\left(3.5 \mathrm{~V} \mathrm{vs} . \mathrm{Li}^{+} / \mathrm{Li}\right)$, 
long life cycle, superior safety, low cost, low toxicity, abundant resources, and lesser environmental impact [7].

To date, many studies have focused on the production of $\mathrm{LiFePO}_{4}$ particles by different methods such as: solid state synthesis [8-10], mechanochemical activation [10,11], sol-gel synthesis [10,12], coprecipitation $[10,13,14]$, and hydrothermal synthesis $[6,10]$, among others [7]. Among all of them, hydrothermal synthesis has been gaining prominence since its capacity to produce extremely pure and crystalline particles using relatively low temperatures $\left(115-400^{\circ} \mathrm{C}\right)[15,16]$ has been demonstrated, and in relatively short reaction times (from seconds to hours) $[17,18]$.

For a long time, the research works that have been conducted on hydrothermal synthesis have primarily focused on the improvement of the two main drawbacks that $\mathrm{LiFePO}_{4}$ presents. These are its low diffusivity $\left(10-14 \mathrm{~cm}^{2} \cdot \mathrm{s}^{-1}\right)$ and its low electrical conductivity $\left(10^{-9} \mathrm{~S} \cdot \mathrm{cm}^{-1}\right)$ [1]. Several studies have tried to find the way to improve lithium ion diffusivity by varying the size and morphology of its particles through the control of the different variables that have an influence on their formation process in order to shorten lithium-ion main diffusion channel ([10] channel): $\mathrm{pH}[19,20]$, reaction time [15,21], stirring [22], temperature [16,23], and use of surface-modifying agents and reducing agents [24-28]. Other studies have tried to improve lithium-ion electrical conductivity by coating its particles with carbon or doping them with transition metals [29-31].

In addition, another important part of the studies on hydrothermal synthesis have been based on the rapid and economic production of $\mathrm{LiFePO}_{4}[17,32]$. To accomplish an efficient production of $\mathrm{LiFePO}_{4}$, continuous processes, where preheating is usually rapid, are required. However, the use of high heating rates may generate large amounts of iron oxide impurities (magnetite) and poor particle crystallization, which prevents good electrochemical performance [33,34]. In our previous work [34], we found that magnetite was generated at heating rates of $86^{\circ} \mathrm{C} / \mathrm{min}$. This did not occur when heating rates of $5.26^{\circ} \mathrm{C} / \mathrm{min}$ were used. In addition, it was noted that the particles were less crystalline when rates of $86^{\circ} \mathrm{C} / \mathrm{min}$ were applied. One alternative approach to avoid magnetite formation consists of the use of reducing agents such as ascorbic acid, pyrrole, urea, sucrose, citric acid, etc. $[25,26,35,36]$ which might increase the cost of the process. The main objective of this work is to reduce the overall process reaction time while obtaining a $\mathrm{LiFePO}_{4}$ as pure as possible, i.e., with less magnetite impurities and without any use of reducing agents. For this purpose, we have focused on the implementation of various combinations of slow and fast heating rates in order to determine the optimal time to start the fast heating step in a process that would start with a slow heating rate. Different hydrothermal synthesis experiments where a slow heating rate from room temperature to $50,100,150,150,200,250$, and $300{ }^{\circ} \mathrm{C}$ was followed by a fast heating stage to reach $300{ }^{\circ} \mathrm{C}$ have been carried out. A particularly crucial phenomenon has been observed in the temperature range between 130 and $150{ }^{\circ} \mathrm{C}$, where slow heating rates produce particles with less magnetite impurities and higher crystallinity.

\section{Materials and Methods}

\subsection{Equipment and Experimental Procedures}

As a first stage of the work, crystalline $\mathrm{LiFePO}_{4}$ particles were synthesized in a $0.3 \mathrm{~L}$ commercially available stainless-steel reactor (bolted closure packless autoclave) described in detail in a previous work [37]. These $\mathrm{LiFePO}_{4}$ particles would be used as a reference or base to be compared with the particles obtained, in the second part of the study ( $14 \mathrm{~mL}$ batch reactors), using the combination of slow and fast heating rates, under the same temperature conditions. The exact moment at which the first crystalline nuclei of $\mathrm{LiFePO}_{4}$ were generated in the reactor was also determined, with the aim of clarifying and solidly supporting the results obtained. The reactors fill ratio was adjusted so that the heating times were as close as possible between the two reactors in order to extrapolate the data.

The procedure to generate the base $\mathrm{LiFePO}_{4}$ consisted of first placing $2.0392 \mathrm{~g}$ of $\mathrm{LiOH} \cdot \mathrm{H}_{2} \mathrm{O}$ and $4.5039 \mathrm{~g}$ of $\mathrm{FeSO}_{4} \cdot 7 \mathrm{H}_{2} \mathrm{O}$ in the reactor. Then, $180 \mathrm{~mL}$ of deionized water 
and $1.248 \mathrm{~mL}$ of $\mathrm{H}_{3} \mathrm{PO}_{4}$ were added, the reactor was closed, and the mixture was stirred and purged with nitrogen to remove the oxygen. The selected molar ratio, in order to adjust the $\mathrm{pH}$ of mixture at 7 , has been the same as the one used for the generation of $\mathrm{LiFePO}_{4}$ particles using different configurations of heating rates in this work, being optimized and described in detail in a previous work [34] (Fe: $\left.\mathrm{PO}_{4}: \mathrm{Li} ; 0.9: 1.2: 2.7\right)$. The reaction medium was then heated up to $300{ }^{\circ} \mathrm{C}$ at a rate of $4{ }^{\circ} \mathrm{C} / \mathrm{min}$ and cooled down to room temperature without stirring. Upon completion of the hydrothermal synthesis experiments, the final solution was collected from the reactor, centrifuged to separate the $\mathrm{LiFePO}_{4}$ particles located at the bottom of the supernatant, and dried by means of an oven at $80{ }^{\circ} \mathrm{C}$. More specific details can be found in our previous work [34].

For the study on the formation of the first crystalline nuclei of $\mathrm{LiFePO}_{4}$, the same procedure was used as for the generation of base $\mathrm{LiFePO}_{4}$. In this case, 3 experiments were carried out, where temperature was raised up to 130,140 , and $150{ }^{\circ} \mathrm{C}$, respectively, at a rate of $4{ }^{\circ} \mathrm{C} / \mathrm{min}$, and then cooled down to room temperature.

For the generation of $\mathrm{LiFePO}_{4}$ particles using different configurations of slow and fast heating rates, two heating systems were combined. The first method, consisting of a sand bath (Techne model TC-8D with a power of $4 \mathrm{~kW}$ ), had been used in our previous work [34]. For the present work, a new method with a fluidized sand bath (Techne model SBL-2 with a power of $3 \mathrm{~kW}$ ) was added. Thus, the heating system was made up of two fluidized sand baths, two compressors that introduced air into the baths to fluidize the sand, a temperature controller, and a reactor manufactured by our research team as detailed in a previous work [34]. The experimental procedure used to fill the $14 \mathrm{~mL}$ volume batch reactors to perform the hydrothermal synthesis of $\mathrm{LiFePO}_{4}$ from the selected reagents, and the separation of the corresponding $\mathrm{LiFePO}_{4}$ microcrystals obtained had been optimized and described in detail in a previous work [34]. The procedure is highly similar to that of the base $\mathrm{LiFePO}_{4}$, only that to enable agitation in small reactors, the necessary water is added in two parts.

\subsection{Reagents, Process Reactions and Products}

The $\mathrm{LiFePO}_{4}$ was generated by means of the following precursors: $\mathrm{LiOH} \cdot \mathrm{H}_{2} \mathrm{O}(99 \%)$, $\mathrm{FeSO}_{4} \cdot 7 \mathrm{H}_{2} \mathrm{O}(98 \%), \mathrm{H}_{3} \mathrm{PO}_{4}(85 \%)$, and deionized water. All the chemicals were supplied by Aldrich Co.

The process to generate the $\mathrm{LiFePO}_{4}$, could be summarized in two stages. The first and shorter stage consists of the dissolution of the initial reagents $\left(\mathrm{FeSO}_{4}+\mathrm{H}_{3} \mathrm{PO}_{4}+3 \mathrm{LiOH}\right)$ in the water, which results in the formation of the intermediated reagents $\left(\mathrm{Li}_{3} \mathrm{PO}_{4}\right.$ and $\left.\mathrm{Fe}_{3}\left(\mathrm{PO}_{4}\right)_{2} \cdot 8 \mathrm{H}_{2} \mathrm{O}\right)$ [38]. During the second stage, the intermediate reagents, first $\mathrm{Li}_{3} \mathrm{PO}_{4}$ and finally $\mathrm{Fe}_{3}\left(\mathrm{PO}_{4}\right)_{2} \cdot 8 \mathrm{H}_{2} \mathrm{O}$, are dissolved to yield $\mathrm{LiFePO}_{4}$ and $\mathrm{Li}_{2} \mathrm{SO}_{4}$ [33]. The $\mathrm{LiFePO}_{4}$ particles are generated when the $\mathrm{Fe}_{3}\left(\mathrm{PO}_{4}\right)_{2} \cdot 8 \mathrm{H}_{2} \mathrm{O}$ liberates $\mathrm{Fe}^{+2}$ into the medium. The global equation for $\mathrm{LiFePO}_{4}$ formation could be expressed as follows:

$$
\mathrm{FeSO}_{4}+\mathrm{H}_{3} \mathrm{PO}_{4}+3 \mathrm{LiOH} \rightarrow \mathrm{LiFePO}_{4}+\mathrm{Li}_{2} \mathrm{SO}_{4}+3 \mathrm{H}_{2} \mathrm{O}
$$

When the heating rate of the reactors during the formation of $\mathrm{LiFePO}_{4}$ is extremely high, large concentrations of $\mathrm{Fe}^{+2}$ are quickly released into the medium, which favors the generation of magnetite $\left(\mathrm{Fe}_{3} \mathrm{O}_{4}\right)$ because of the Schikorr reaction [39].

Schikorr reaction:

$$
\begin{gathered}
2\left(\mathrm{Fe}^{+2} \rightarrow \mathrm{Fe}^{+3}+\mathrm{e}^{-}\right) \\
2\left(\mathrm{H}_{2} \mathrm{O}+\mathrm{e}^{-} \rightarrow 1 / 2 \mathrm{H}_{2}+\mathrm{OH}^{-}\right) \\
2 \mathrm{Fe}^{+2}+2 \mathrm{H}_{2} \mathrm{O} \rightarrow 2 \mathrm{Fe}^{+3}+\mathrm{H}_{2}+2 \mathrm{OH}^{-}
\end{gathered}
$$

The presence of the $\mathrm{Fe}^{+2}$ leads to:

$$
3 \mathrm{Fe}^{+2}+2 \mathrm{H}_{2} \mathrm{O} \rightarrow \mathrm{Fe}^{+2}+2 \mathrm{Fe}^{+3}+\mathrm{H}_{2}+2 \mathrm{OH}^{-}
$$


Electroneutrality requires the iron cations on both sides of the equation to be counterbalanced by 6 hydroxyl anions $\left(\mathrm{OH}^{-}\right)$:

$$
\begin{gathered}
3 \mathrm{Fe}^{+2}+6 \mathrm{OH}^{-}+2 \mathrm{H}_{2} \mathrm{O} \rightarrow \mathrm{Fe}^{+2}+2 \mathrm{Fe}^{+3}+\mathrm{H}_{2}+8 \mathrm{OH}^{-} \\
3 \mathrm{Fe}(\mathrm{OH})_{2}+2 \mathrm{H}_{2} \mathrm{O} \rightarrow \mathrm{Fe}(\mathrm{OH})_{2}+2 \mathrm{Fe}(\mathrm{OH})_{3}+\mathrm{H}_{2}
\end{gathered}
$$

Due to the autoproteolysis of the hydroxyl anions:

$$
\mathrm{OH}^{-}+\mathrm{OH}^{-} \rightarrow \mathrm{O}^{-2}+\mathrm{H}_{2} \mathrm{O}
$$

Therefore:

$$
\begin{gathered}
3 \mathrm{Fe}(\mathrm{OH})_{2}+2 \mathrm{H}_{2} \mathrm{O} \rightarrow\left(\mathrm{FeO}+1 \mathrm{H}_{2} \mathrm{O}\right)+\left(\mathrm{Fe}_{2} \mathrm{O}_{3}+3 \mathrm{H}_{2} \mathrm{O}\right)+\mathrm{H}_{2} \\
3 \mathrm{Fe}(\mathrm{OH})_{2} \rightarrow \mathrm{FeO}+\mathrm{Fe}_{2} \mathrm{O}_{3}+2 \mathrm{H}_{2} \mathrm{O}+\mathrm{H}_{2}
\end{gathered}
$$

Finally, following the magnetite formation the following reaction takes place:

$$
\mathrm{FeO}+\mathrm{Fe}_{2} \mathrm{O}_{3} \rightarrow \mathrm{Fe}_{3} \mathrm{O}_{4}
$$

Therefore, by increasing the $\mathrm{Fe}^{+2}$ concentration in the medium, the Schikorr reaction might accelerate.

In order to evaluate the possibility of improving the overall process, this study has focused in detailed the effect caused by different heating configurations, so that increments in the heating rate can be applied at different times during the hydrothermal synthesis. Thus, this influence from the different heating configurations has been closely analyzed to determine the critical temperature levels during the heating stage where a high heating rate can be implemented to improve the $\mathrm{LiFePO}_{4}$ synthesis process, not only in terms of the crystallinity, morphology, and purity of the particles, but also with regard to the feasibility of the process.

\subsection{Formation of the Base $\mathrm{LiFePO}_{4}$}

In order to carry out an adequate comparison of the crystallinity, purity, and morphology of the particles obtained from the subsequent experiments, we previously produced our own $\mathrm{LiFePO}_{4}$ particles to be used as a reference. These will be referred to here as the "base $\mathrm{LiFePO}_{4}$ ". Such base $\mathrm{LiFePO}_{4}$ particles have to be generated under tightly controlled temperature and heating rate conditions (See Figure 1) according to the literature $[15,16,18,23,24,40]$. The reactor and experimental procedure have been described in Section 2.1. The base experiment was carried out under the same conditions as the rest of the experiments conducted in this work: i.e., the reaction medium was heated up to $300^{\circ} \mathrm{C}$, reached a pressure of $103 \mathrm{bar}$, was held under such conditions for $5 \mathrm{~min}$, and then slowly cooled down to room temperature. 


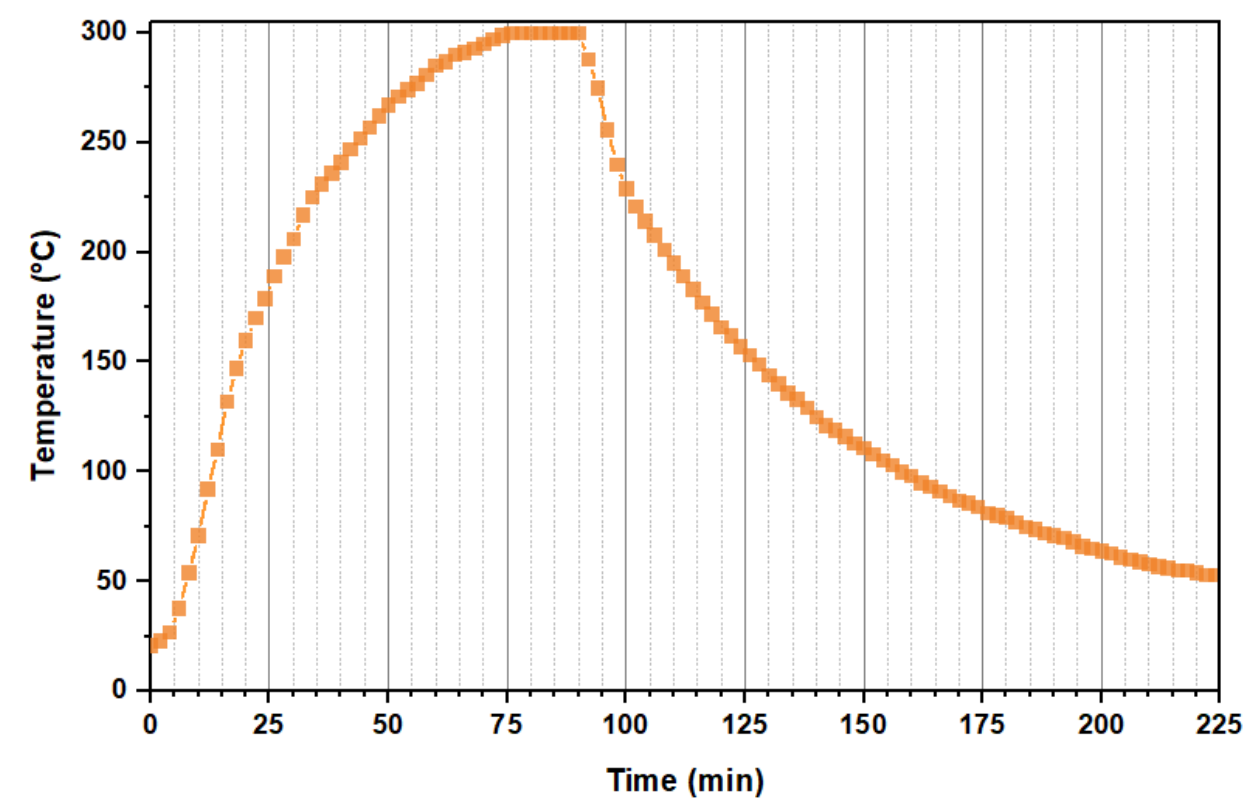

Figure 1. Temperature profile of the reaction medium during the hydrothermal synthesis of the base $\mathrm{LiFePO}_{4}$.

\subsection{Study of the Formation of the First Crystalline Nuclei of $\mathrm{LiFePO}_{4}$}

In order to perform an accurate analysis of the results from this study, it is necessary to determine the exact moment when the first crystalline nuclei of $\mathrm{LiFePO}_{4}$ appear. Given that $\mathrm{LiFePO}_{4}$ is generated when $\mathrm{Fe}_{3}\left(\mathrm{PO}_{4}\right)_{2}-8 \mathrm{H}_{2} \mathrm{O}$ begins to dissolve, and that this depends on the length of time required to heat the reaction medium, such length of time required by our reactors should be precisely determined in order to clarify this key point regarding the purity and crystallization of $\mathrm{LiFePO}_{4}$. According to the study carried out by J. Lee and A.S. Teja [16], the formation of the first crystalline nuclei would take place when the medium reaches between 120 and $190{ }^{\circ} \mathrm{C}$, since only $\mathrm{Fe}_{3}\left(\mathrm{PO}_{4}\right)_{2}-8 \mathrm{H}_{2} \mathrm{O}$ appeared in the samples obtained at $120^{\circ} \mathrm{C}$, while the $\mathrm{LiFePO}_{4}$ particles were already visible in the samples produced at $190^{\circ} \mathrm{C}$. On the other hand, C. Min et al. [40], established that a large amount of $\mathrm{LiFePO}_{4}$ nuclei are rapidly formed when the medium temperature reaches values around $124-130{ }^{\circ} \mathrm{C}$.

Considering the temperatures that have been already studied in the bibliography, the experiments were conducted at 130,140 , and $150^{\circ} \mathrm{C}$ (reaching $1.01,6.55$ and 7.58 bar, respectively). The reactor and the experimental procedures have been described in Section 2.1.

\subsection{Formation and Separation of $\mathrm{LiFePO}_{4}$ Microcrystals}

The reactor heating procedure was as follows: First, the reactor was submerged into one of the fluidized sand baths still at room temperature (the bath heating system had not been turned on yet). Once inside, the sand bath was turned on and a slow heating rate of $4.44^{\circ} \mathrm{C} / \mathrm{min}$ was applied. When the target temperature set for each experiment was reached, the reactor was submerged into another sand bath, which had been previously heated and maintained at a constant temperature of $300^{\circ} \mathrm{C}$. Therefore, from the moment the reactor was submerged into the second sand bath until the moment the reactor reached $300{ }^{\circ} \mathrm{C}$, the medium was subjected to a fast heating rate. Thereafter, the reactor was maintained at $300^{\circ} \mathrm{C}$ for $5 \mathrm{~min}$ (reaction time) before being removed from the sand bath and kept in contact with the laboratory air until completely cooled down to room temperature (see Figure 2). Thus, the final reaction temperature was the same for all the experiments, but the heating time, and therefore the total time of each experiment, which comprises the heating time plus the $5 \mathrm{~min}$ reaction time at $300^{\circ} \mathrm{C}$, was different. 


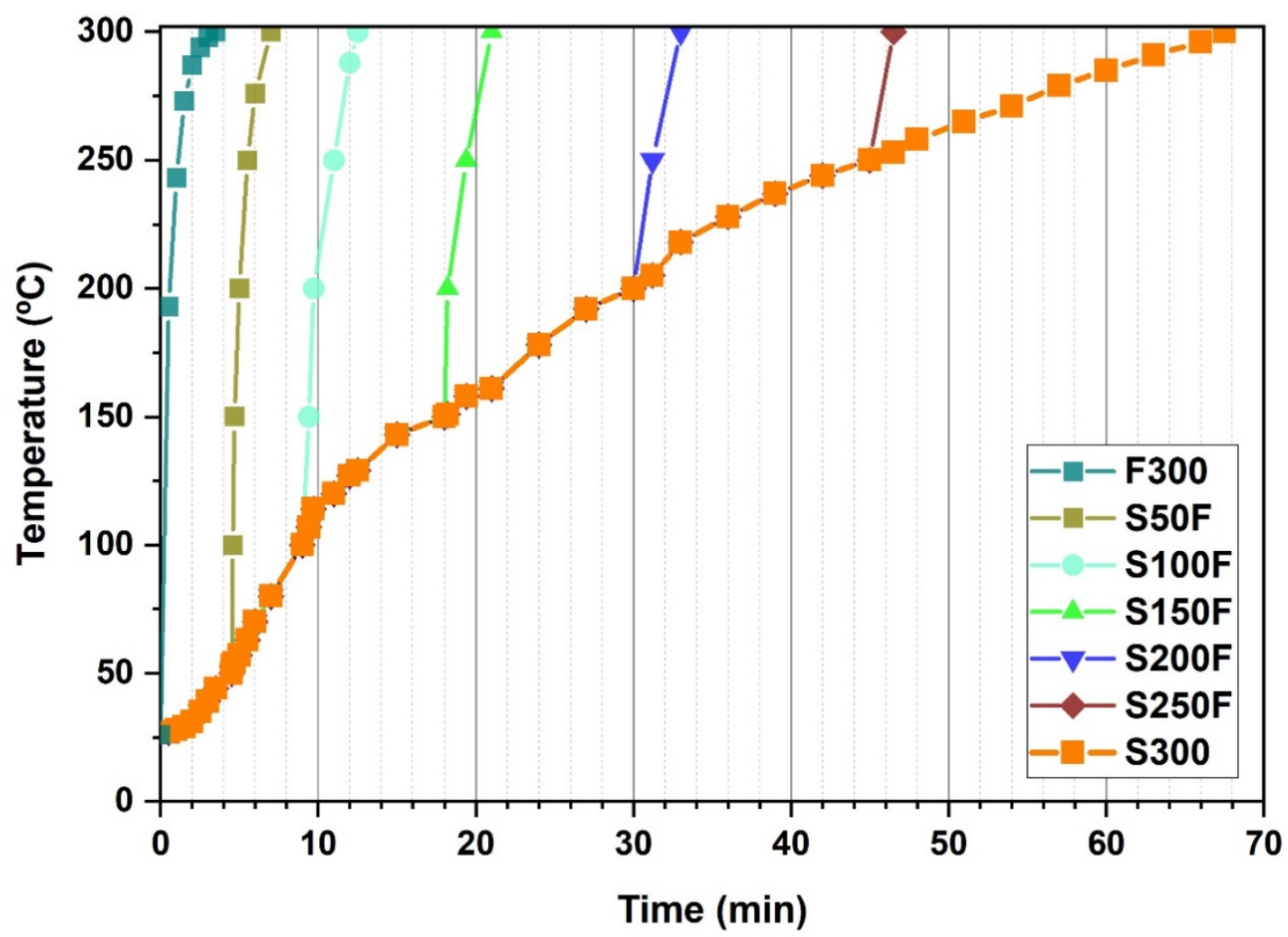

Figure 2. Temperature profile of the reaction medium during the combined slow-fast heating experiments to form $\mathrm{LiFePO}_{4}$ microcrystalline particles.

Table 1 includes the operating conditions of the different hydrothermal synthesis (HS) experiments that combine slow and fast heating. In addition, in order to further consider the configuration range to be tested, two experiments with only one type of heating were carried out: (i) thus, experiment F300 was only subjected to fast heating up to $300{ }^{\circ} \mathrm{C}$, while (ii) experiment $\mathrm{S} 300$ was only subjected to slow heating up to the same temperature. Figure 2 shows the evolution of the temperature profiles of the reaction medium over time for the HS experiments included in Table 1.

Table 1. Nomenclature of the samples and their corresponding experimental conditions. All the samples were heated up to $300^{\circ} \mathrm{C}$ and subjected to 110 bars of pressure.

\begin{tabular}{ccccc}
\hline HS Experiments & $\begin{array}{c}\text { Slow Heating } \\
\mathbf{T}_{\mathbf{0}}\left({ }^{\circ} \mathbf{C}\right)\end{array}$ & $\begin{array}{c}\text { Fast Heating } \\
\mathbf{T}_{\mathbf{0}}\left({ }^{\circ} \mathbf{C}\right)\end{array}$ & $\begin{array}{c}\text { Reaction Time } \\
(\mathbf{m i n})\end{array}$ & $\begin{array}{c}\text { Total Time Length of } \\
\text { the Synthesis Process } \\
*(\mathbf{m i n})\end{array}$ \\
\hline F300 & - & 300 & 5 & $0+3.5+5=8.5$ \\
S50F & 50 & 300 & 5 & $4.5+3+5=12.5$ \\
S100F & 100 & 300 & 5 & $9+3+5=17$ \\
S150F & 150 & 300 & 5 & $18+3+5=26$ \\
S200F & 200 & 300 & 5 & $30+2.5+5=37.5$ \\
S250F & 250 & 300 & 5 & $45+2+5=52$ \\
S300 & 300 & - & 5 & $67.5+0+5=72.5$ \\
\hline
\end{tabular}

* Total time length of the synthesis process: slow heating + fast heating + reaction time.

Once the hydrothermal synthesis experiments were completed, the final solution was collected from the reactor, centrifuged, and dried, following the procedure already explained in Section 2.1. 


\subsection{Characterization}

The structural properties of $\mathrm{LiFePO}_{4}$ particles were analyzed by X-ray diffraction (XRD) by means of a Bruker D8 Discover A25 diffractometer (Bruker Española S.A., Madrid, Spain) using $\mathrm{Cu} \mathrm{K} \alpha$ radiation, Ge monochromator, and a Lynxeye detector. The patterns were registered within the $10-80^{\circ}(2 \theta)$ range, according to a $140 \mathrm{~s}$. step time. The lattice cell parameters, the crystallite size and the amount of impurities present in the synthesized $\mathrm{LiFePO}_{4}$ were calculated using Topas software (Bruker Española S.A., Madrid, Spain) according to the full pattern matching method. The morphological properties of the samples were determined by means of a field-emission scanning electron microscope (FESEM) using a FEI-Nova Nano SEM 450 instrument (Izasa Scientific, Madrid, Spain). The presence of magnetite impurities in the synthesized $\mathrm{LiFePO}_{4}$ was verified by X-ray diffraction and also by our own-built electromagnet to confirm the magnetic behavior of the samples.

\section{Results and Discussion}

\subsection{Analysis of the Synthesized Base $\mathrm{LiFePO}_{4}$}

The purity and crystallinity of the synthesized base $\mathrm{LiFePO}_{4}$ was determined by XRD. Figure 3 shows the XRD pattern of the $\mathrm{LiFePO}_{4}$ powders synthesized in the $\mathrm{HS}$ base experiment, where the peaks in the different diffractograms closely match the standard $\mathrm{LiFePO}_{4}$ pattern (JCPDS card no. PDF 40-1267). Moreover, no impurities (no magnetite) were detected in the diffractogram.

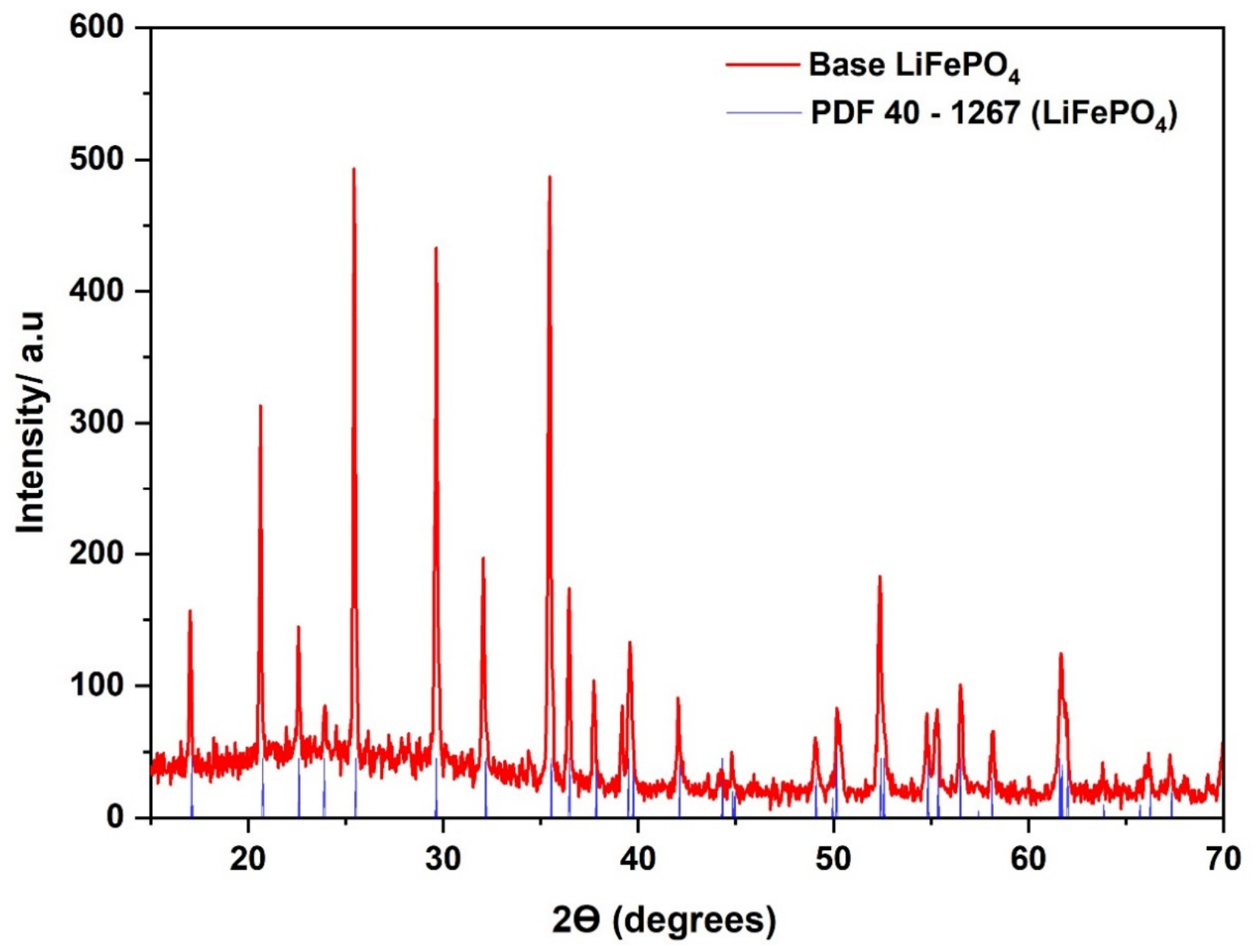

Figure 3. XRD pattern of the synthesized base $\mathrm{LiFePO}_{4}$. 
The refinement of the lattice parameters for the orthorhombic structure of the base $\mathrm{LiFePO}_{4}$ with the Pnma space group provided the following values: $\mathrm{a}=10.3328 \AA$, $\mathrm{b}=6.0043 \AA$, and $\mathrm{c}=4.6977 \AA$, which is in accordance with the literature [41].

The crystallinity of the particles obtained in the base experiment was considered optimum, and, therefore, they were suitable to be used as the reference for this study. That is, the particles obtained from the experiments, where different combinations of slow heating and fast heating was implemented, were to be mainly compared against the crystallinity of the base $\mathrm{LiFePO}_{4}$.

Figure 4 displays SEM images of the base $\mathrm{LiFePO}_{4}$, where flat and well-defined microparticles can be observed. Its morphology is dominated by face (010) that corresponds to diamond-shaped crystallites [42]. Thus, diamond-shaped platelets are less than $1 \mathrm{mi}-$ cron thick and their dimensions vary between 2-4 microns for the shortest diagonal and 6-8 microns for the longest one.
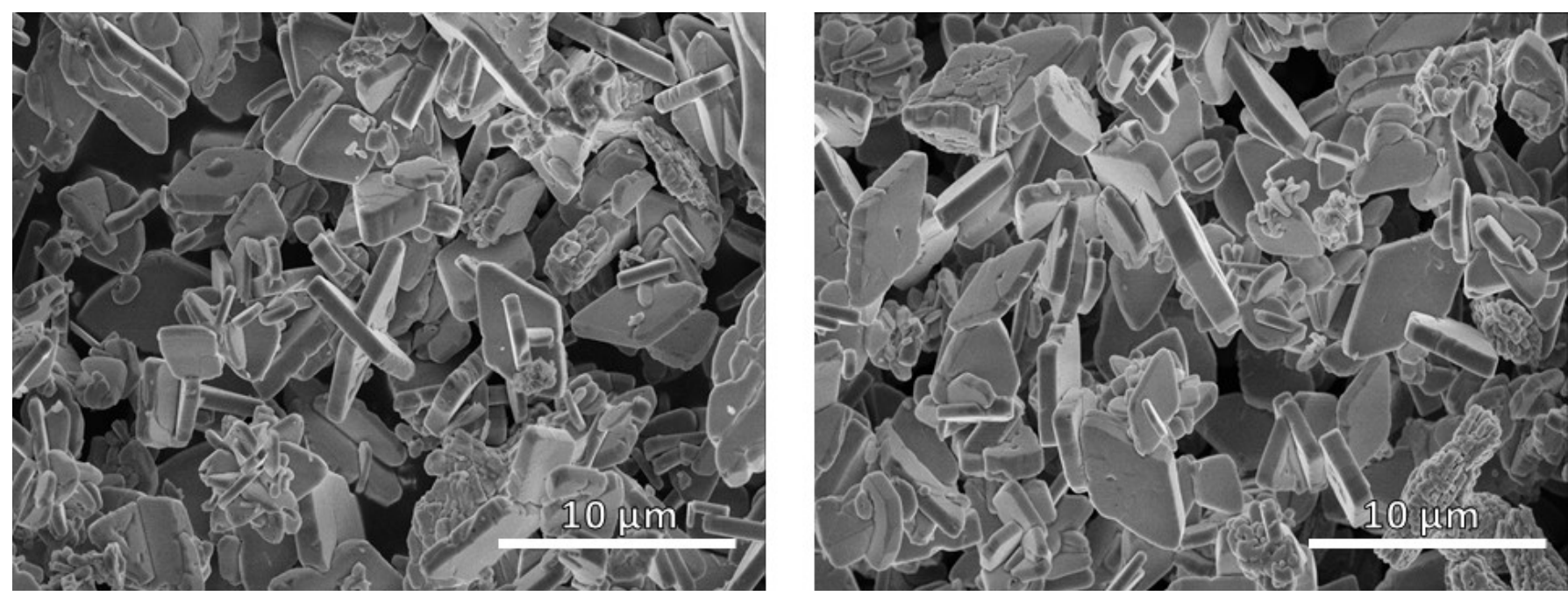

Figure 4. SEM micrographs of the synthesized base $\mathrm{LiFePO}_{4}$ obtained from the HS base experiment (two random areas of the sample are displayed).

\subsection{Study on the Formation of the First Crystalline Nuclei of $\mathrm{LiFePO}_{4}$}

Figure 5 shows the XRD pattern of synthesized $\mathrm{LiFePO}_{4}$ powders produced at different temperatures: 130,140 , and $150{ }^{\circ} \mathrm{C}$. As can be observed, the samples that had been synthesized at 140 and $150^{\circ} \mathrm{C}$ present the characteristic peaks that can be attributed to the orthorhombic olivine structure of $\mathrm{LiFePO}_{4}$. However, the sample that had been synthesized at $130{ }^{\circ} \mathrm{C}$ presented no evidence of any $\mathrm{LiFePO}_{4}$ content. Although, as previously mentioned, Min et al. [34] established that a large amount of $\mathrm{LiFePO}_{4}$ nuclei were formed in the $124-130{ }^{\circ} \mathrm{C}$ range. $\mathrm{Fe}_{3}\left(\mathrm{PO}_{4}\right)_{2}-8 \mathrm{H}_{2} \mathrm{O}$ may be soluble within that temperature range albeit the heating time employed in this study may have not been long enough to allow the generation of the first crystalline nuclei of $\mathrm{LiFePO}_{4}$. Therefore, even though it cannot be affirmed that the first $\mathrm{LiFePO}_{4}$ crystalline nuclei are necessarily formed between 124 and $130{ }^{\circ} \mathrm{C}$, it can be presumed that $\mathrm{Fe}_{3}\left(\mathrm{PO}_{4}\right)_{2}-8 \mathrm{H}_{2} \mathrm{O}$ begins to dissolve at around $130{ }^{\circ} \mathrm{C}$, so that this temperature level might be key to explain much of what happens in this process, which would make it worth a deeper discussion, as can be seen in Section 3.3. 


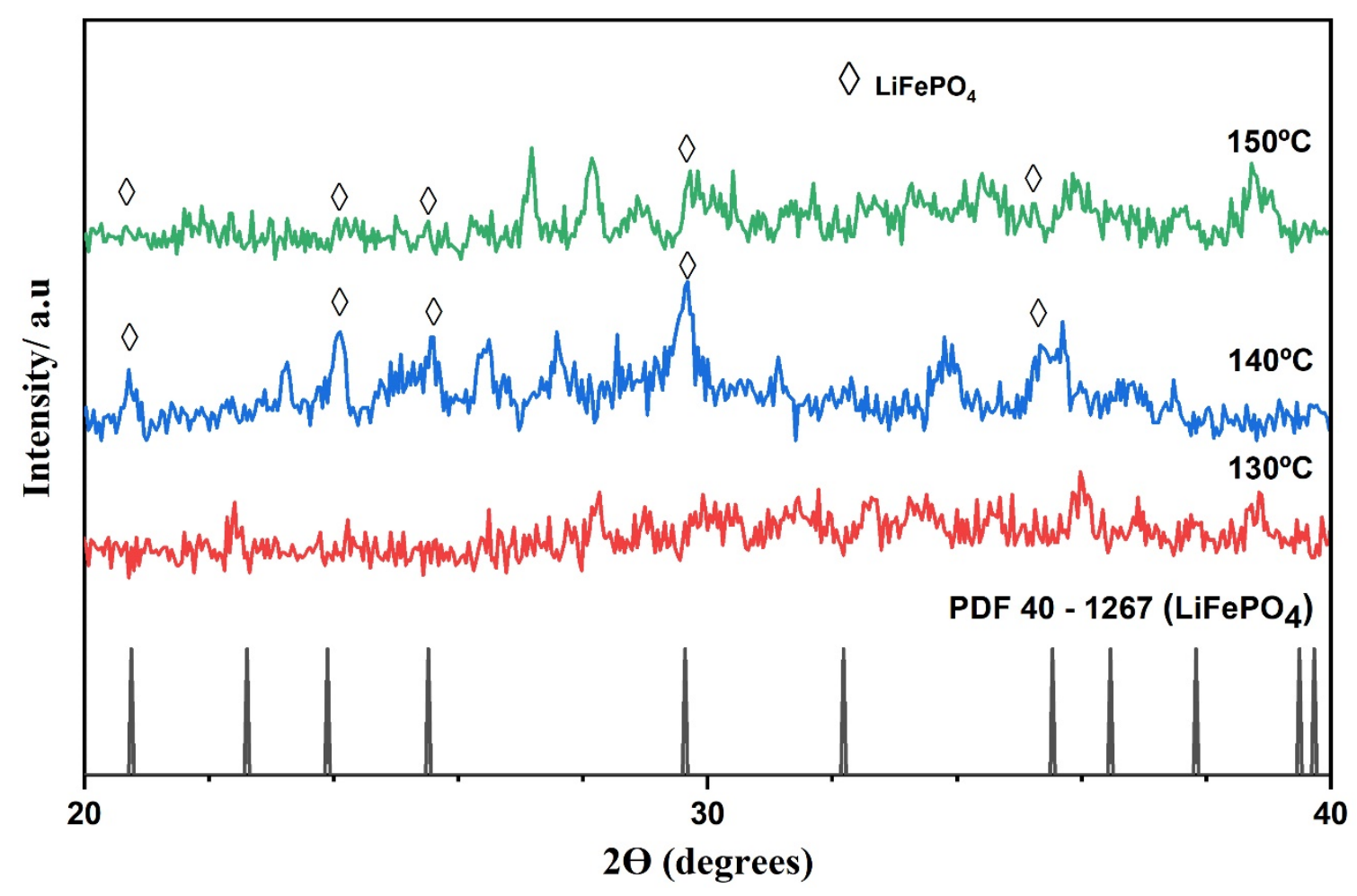

Figure 5. XRD patterns of the $\mathrm{LiFePO}_{4}$ particles obtained by hydrothermal synthesis at 130,140 and $150{ }^{\circ} \mathrm{C}$.

\subsection{Study on the Combination of Slow-Fast Heating Rates during the HS of $\mathrm{LiFePO}_{4}$ Particles}

\subsubsection{Crystallinity and Purity of the $\mathrm{LiFePO}_{4}$ Particles}

The purity and crystallinity of the synthesized particles was determined by XRD. Figure 6 shows the XRD patterns of $\mathrm{LiFePO}_{4}$ powders generated through the different experiments included in Table 1 and that corresponding to the base HS experiment. The peaks in all of the diffractograms closely match the reference pattern (JCPDS card no. PDF 40-1267). Therefore, the hydrothermal synthesis of $\mathrm{LiFePO}_{4}$ particles has been confirmed for all the experiments that have been carried out. On the other hand, the XRD patterns revealed magnetite impurities in some of the samples, as can be seen in Figure 6.

Table 2 shows that only pure $\mathrm{LiFePO}_{4}$ particles were generated in experiments $\mathrm{S} 300$ and S250F. On the other hand, all the particles that had been obtained from the experiments that implemented a fast heating rate before reaching $250{ }^{\circ} \mathrm{C}$ (F300, S50F, S100F, S150F, and S200F) presented magnetite impurities to a greater or lesser degree. This could be due to the dissolved form of $\mathrm{Fe}_{3}\left(\mathrm{PO}_{4}\right)_{2} \cdot 8 \mathrm{H}_{2} \mathrm{O}$. It has been already mentioned (Section 2.2) that $\mathrm{LiFePO}_{4}$ is generated when $\mathrm{Fe}_{3}\left(\mathrm{PO}_{4}\right)_{2} \cdot 8 \mathrm{H}_{2} \mathrm{O}$ releases $\mathrm{Fe}^{+2}$ into the medium, and this occurs at around $130{ }^{\circ} \mathrm{C}$. Therefore, the generation of magnetite in samples F300, S50F, S100F, S150F, and S200F could be due to the high concentration of $\mathrm{Fe}^{+2}$ in the medium generated by the rapid solubilization of $\mathrm{Fe}_{3}\left(\mathrm{PO}_{4}\right)_{2} \cdot 8 \mathrm{H}_{2} \mathrm{O}$, which in turn would allow the anaerobic oxidation of $\mathrm{Fe}^{+2}$ into $\mathrm{Fe}^{+3}$ by the water in the medium, as described by Schikorr reaction. On the other hand, the absence of magnetite in the samples S300 and S250F could be explained by the slow and gradual solubilization of most of the $\mathrm{Fe}_{3}\left(\mathrm{PO}_{4}\right)_{2} \cdot 8 \mathrm{H}_{2} \mathrm{O}$, which did not cause the medium $\mathrm{Fe}^{+2}$ supersaturation. It is worth noting that substantial differences could be observed between the amount of magnetite generated in the F300, S50F, and S100F samples (higher magnetite peaks) against that generated in the S150F and S200F samples (lower magnetite peaks). This lesser amount of magnetite impurities could be mainly explained by the two following factors: firstly, a slow heating rate implemented over the solubilization stage of the $\mathrm{Fe}_{3}\left(\mathrm{PO}_{4}\right)_{2} \cdot 8 \mathrm{H}_{2} \mathrm{O}$, (from $130{ }^{\circ} \mathrm{C}$ until $150{ }^{\circ} \mathrm{C}$ and from $130{ }^{\circ} \mathrm{C}$ until $200{ }^{\circ} \mathrm{C}$; respectively) that causes the $\mathrm{Fe}^{+2}$ to be generated progressively in the medium, and thus the Schikorr reaction is minimized; secondly, at $150{ }^{\circ} \mathrm{C}$, a certain amount 
of $\mathrm{LiFePO}_{4}$ has already been generated and, consequently, there is a smaller amount of $\mathrm{Fe}^{+2}$ in the medium.
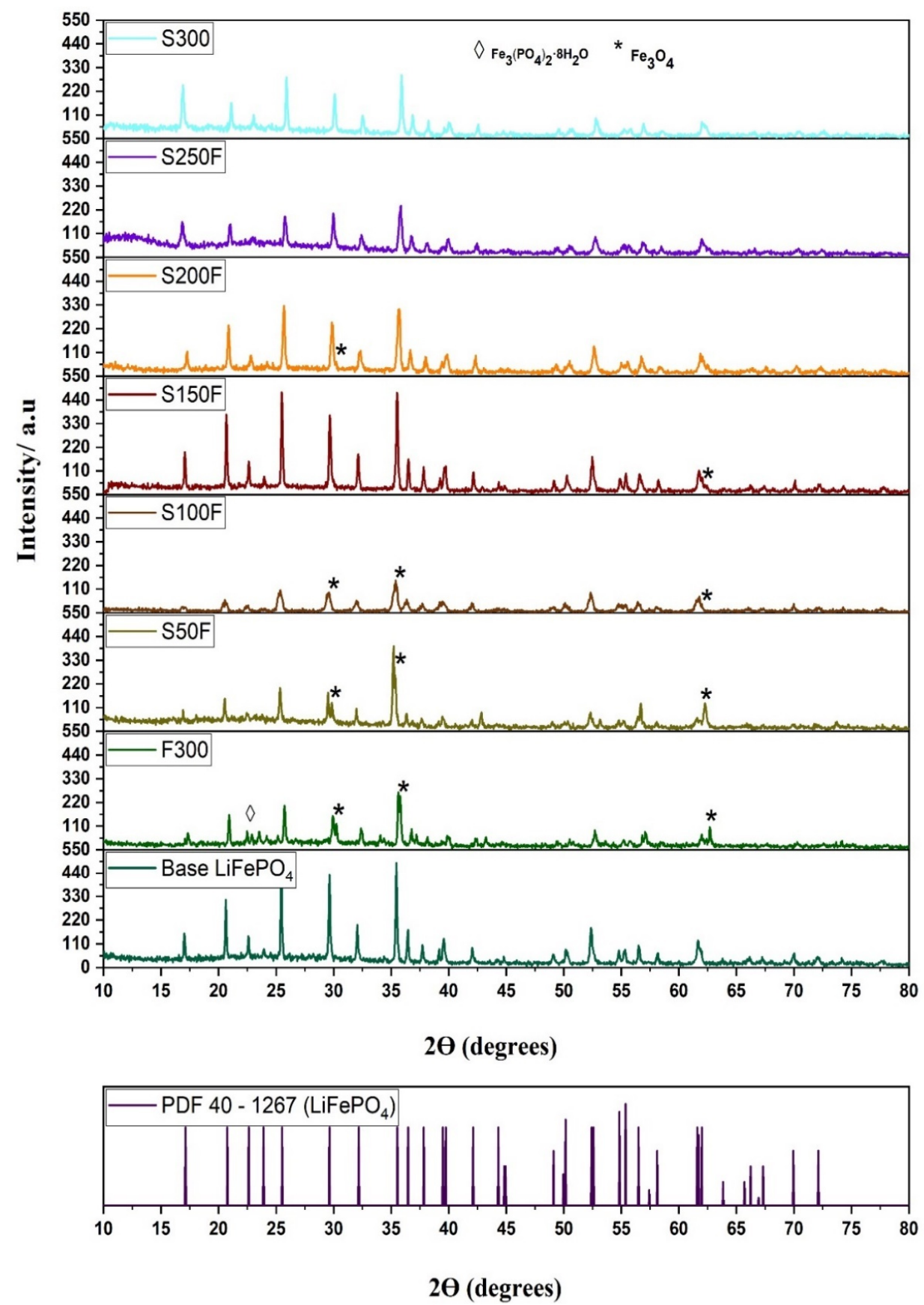

Figure 6. XRD patterns of hydrothermally synthesized $\mathrm{LiFePO}_{4}$.

Table 2. Crystalline phases found in the $\mathrm{XRD}$ patterns of the synthesized $\mathrm{LiFePO}_{4}$ particles.

\begin{tabular}{cc}
\hline HS Experiment & Crystalline Phases \\
\hline F300 & $\mathrm{LiFePO}_{4}+\mathrm{Fe}_{3} \mathrm{O}_{4}+\mathrm{Fe}_{3}\left(\mathrm{PO}_{4}\right)_{2} \cdot 8 \mathrm{H}_{2} \mathrm{O}$ \\
S50F & $\mathrm{LiFePO}_{4}+\mathrm{Fe}_{3} \mathrm{O}_{4}$ \\
S100F & $\mathrm{LiFePO}_{4}+\mathrm{Fe}_{3} \mathrm{O}_{4}$ \\
S150F & $\mathrm{LiFePO}_{4}+\mathrm{Fe}_{3} \mathrm{O}_{4}$ \\
S200F & $\mathrm{LiFePO}_{4}+\mathrm{Fe}_{3} \mathrm{O}_{4}$ \\
S250F & $\mathrm{LiFePO}_{4}$ \\
S300 & $\mathrm{LiFePO}_{4}$ \\
\hline
\end{tabular}


Regarding crystallinity (see Figure 6), significant differences can also be observed between the F300 S50F, S100F samples and the S150F, S200F, S250F, S300 samples. Thus, the former samples were less crystalline when compared with the base $\mathrm{LiFePO}_{4}$, which could be due to the rapid generation and growth rate of the $\mathrm{LiFePO}_{4}$ particles as a consequence of the medium $\mathrm{Fe}^{+2}$ supersaturation. Consequently, this rapid particle growth would lead to a poor crystallization, i.e., a poor rearrangement of the atoms in space. On the other hand, the latter samples, which had been subjected to slow heating over $130{ }^{\circ} \mathrm{C}$, presented a substantially improved crystallization. Particularly, the samples from experiment S150F exhibited an optimum crystallization level. In fact, the samples obtained at temperatures over $130{ }^{\circ} \mathrm{C}$ did not present any improved crystallinity but rather a poorer one was observed. According to our previous study [34], maintaining the $\mathrm{LiFePO}_{4}$ particles at high temperatures $\left(300^{\circ} \mathrm{C}\right)$ for a long time would negatively affect their crystallinity. This could explain why the sample from experiment S150F was the most crystalline, given that the $\mathrm{LiFePO}_{4}$ particles that had been formed in the 130 to $150{ }^{\circ} \mathrm{C}$ temperature range took just around $8.5 \mathrm{~min}$ to reach $300{ }^{\circ} \mathrm{C}$ from the moment they had been formed. This means that the length of time that they were subjected to high temperatures was relatively short (see Table 3). The high crystallinity of the S150F sample can be seen in Figure 7, where it is compared against the base sample and a close similarity can be observed.

Table 3. Approximate times to reach operation temperatures.

\begin{tabular}{cccc}
\hline HS Experiments & $\mathbf{T}_{\mathbf{i}}{ }^{*}$ & $\mathbf{T}_{\mathbf{s}}{ }^{*}$ & $\mathbf{T}_{\mathbf{f}}{ }^{*}$ \\
\hline S150F & 12.5 & 5.5 & 3 \\
S200F & 12.5 & 17.5 & 2.5 \\
S250F & 12.5 & 32.5 & 2 \\
S300 & 12.5 & 55 & -
\end{tabular}

* $\mathrm{T}_{\mathrm{i}}$ : Time elapsed from the beginning of the heating of the reactor until the moment the first crystalline nuclei of $\mathrm{LiFePO}_{4}$ are formed. ${ }^{*} \mathrm{~T}_{\mathrm{s}}$ : Time elapsed from the moment that the first crystalline nuclei of $\mathrm{LiFePO}_{4}$ are formed until fast heating is implemented. ${ }^{*} \mathrm{~T}_{\mathrm{f}}$ : Time elapsed from the moment that fast heating is implemented and $300^{\circ} \mathrm{C}$ is reached.

Therefore, an abrupt change with respect to the generation of magnetite impurities and crystallinity was observed between the S100F and S150F samples that would allow to separate them into two groups as follows: samples F300, S50F, and S100F would fall into the low crystalline particles with extremely high magnetite peaks; while samples S150F, S200F, S250F, and S300 would be classified as highly crystalline particles with low or no magnetite peaks. Figure 7 shows the XRD patterns in more detail, so that the characteristic peak of the base $\mathrm{LiFePO}_{4}$ as well as those of S100F, S150F, and S200F samples can be observed. Furthermore, Figure 7 includes the diffractogram of the $\mathrm{LaB}_{6}$ sample, which was measured under the same conditions as the base $\mathrm{LiFePO}_{4}$ and the S100F, S150F, and S200F samples, so that their crystallite size would be more accurately measured after removing the instrumental broadening. The full widths at half maximum (FWHM) of the peaks (101), (301), and (311) of the synthesized samples were considered to determine the size of the crystallite $(D)$ according to Debye-Scherrer equation:

$$
D=\frac{k \lambda}{\beta \cos \theta}
$$

where $\lambda$ is the $X$-ray wavelength in nanometers $(\mathrm{nm}), \beta$ is the full width at half maximum of the peak in radians, $\theta$ is the scattering angle in radians, and $k$ is a constant related to crystallite shape, at 0.9 for the Bragg reflections of $\mathrm{LiFePO}_{4}$. The instrumental broadening effect on FWHM was removed using Warren's method on the assumption of a Gaussian peak [43]:

$$
\beta^{2}=\beta_{\text {sample }}^{2}-\beta_{\text {instrumental }}^{2}
$$


where $\beta_{\text {instrumental }}$ is referred to $\mathrm{LaB}_{6}$ peaks at $21.64^{\circ}, 30.43^{\circ}$, and $37.35^{\circ}$ associated with the planes (101), (301), and (311) of the $\mathrm{LiFePO}_{4}$ samples, and correspond to the values of 0.079 , 0.075 , and 0.067 , respectively.

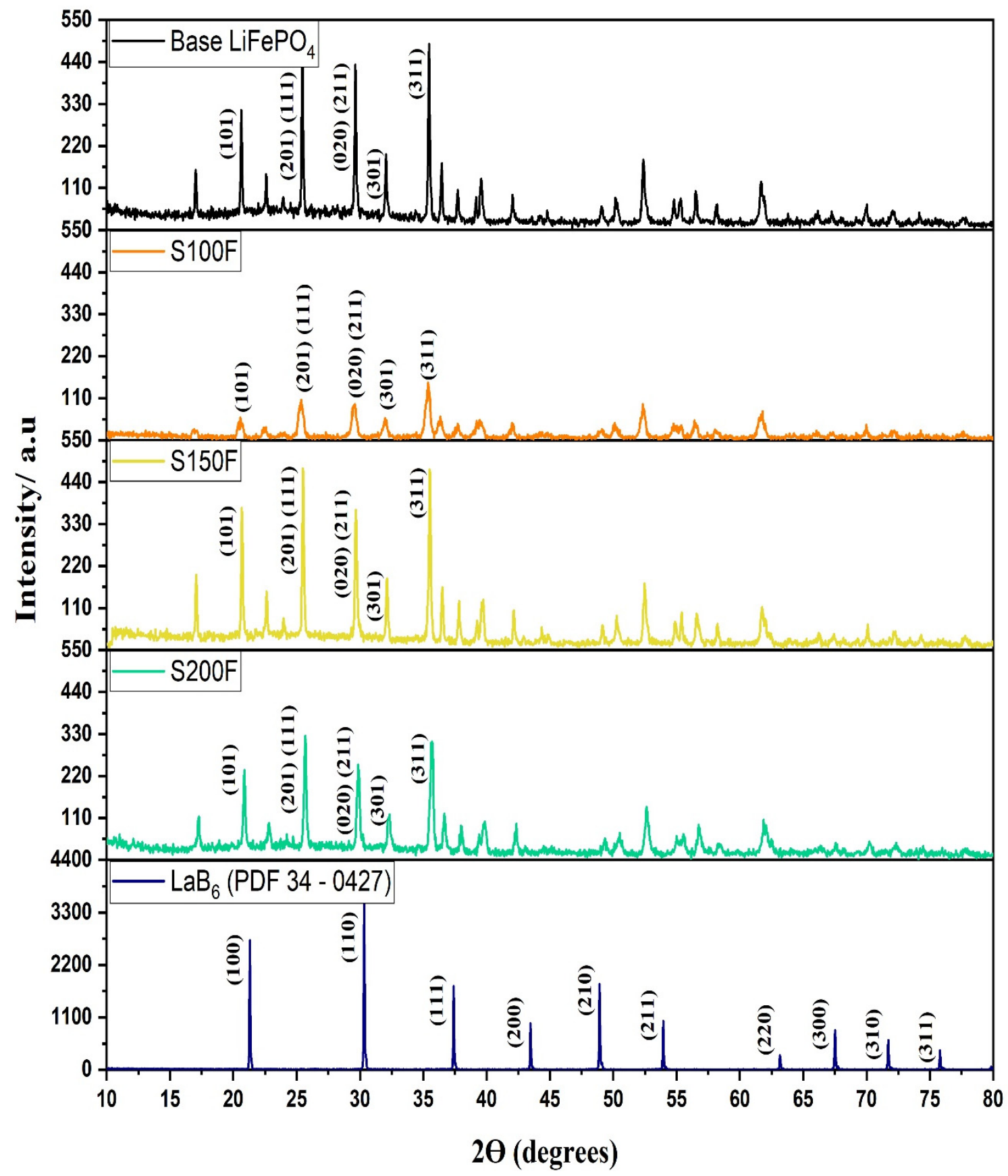

Figure 7. XRD patterns of synthesized Base $\mathrm{LiFePO}_{4}$ vs. S150F. The $\mathrm{LaB}_{6}$ sample (blue line) was used as the benchmark to determine the instrumental broadening.

Table 4 shows that the lattice parameters of the $\mathrm{LiFePO}_{4}$ particles were similar for all the samples. The Scherrer crystallite size (D) was much smaller than the particle size in every case. The average size of the base $\mathrm{LiFePO}_{4}$ sample was $82.5 \mathrm{~nm}$, while the S150F sample was $34.26 \mathrm{~nm}$, the S150F sample was $66.6 \mathrm{~nm}$ and the S200F sample was $39.23 \mathrm{~nm}$ according to Scherrer's equation. Therefore, $\mathrm{D}_{\text {base }} \mathrm{LiFePO}_{4}>\mathrm{D}_{\mathrm{S} 150 \mathrm{~F}} \mathrm{LiFePO}_{4}>\mathrm{DS} 100 \mathrm{~F}$ $\mathrm{LiFePO}_{4}>\mathrm{D}_{\mathrm{S} 200 \mathrm{~F}} \mathrm{LiFePO}_{4}$ due to a further growth of the crystals during the synthesis process. This claim can be confirmed by comparing the following SEM images: base $\mathrm{LiFePO}_{4}$ (Figure 3), S100F, S150F, and S200F (Figure 8B-D, respectively). 

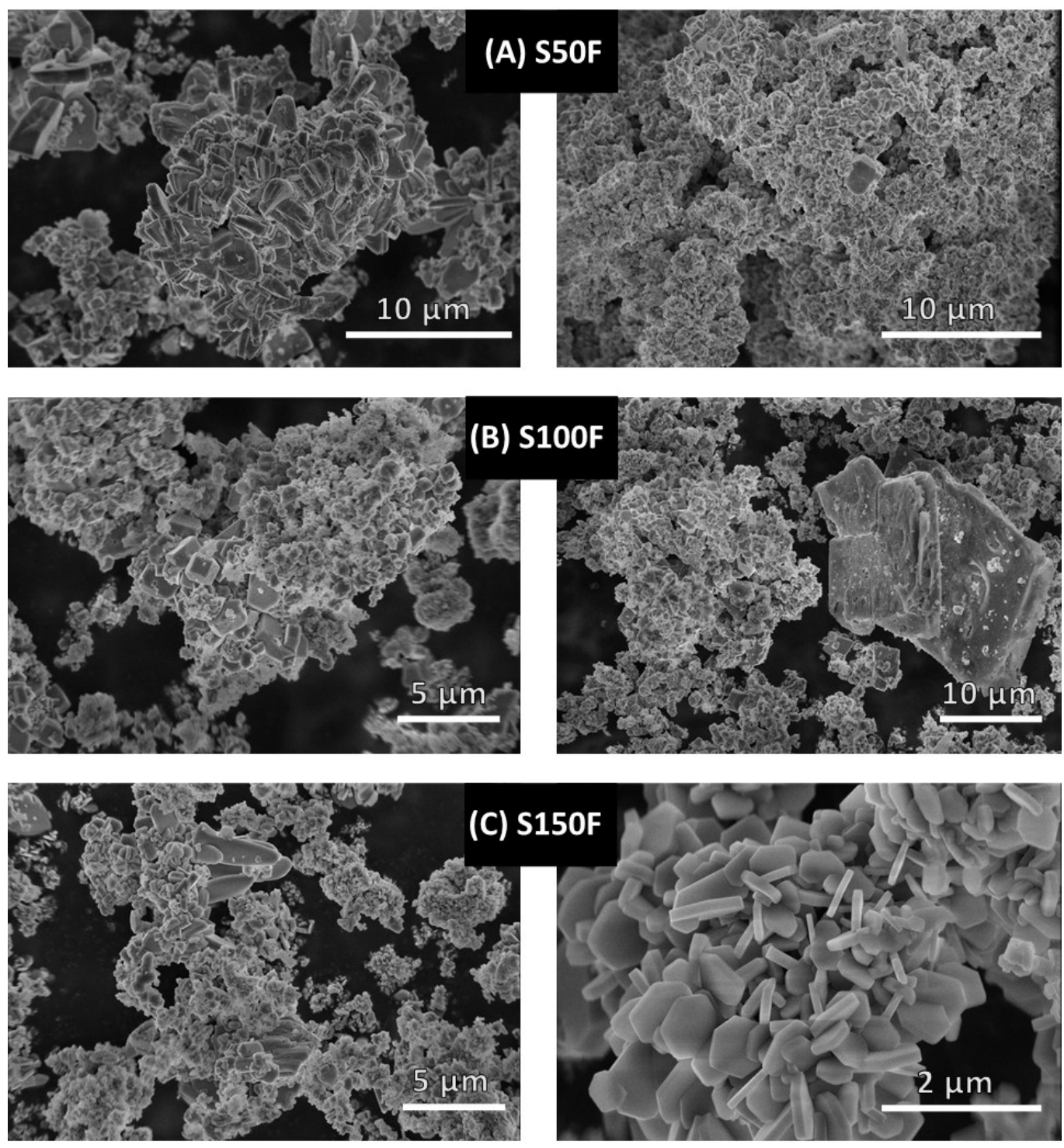

C) S150F

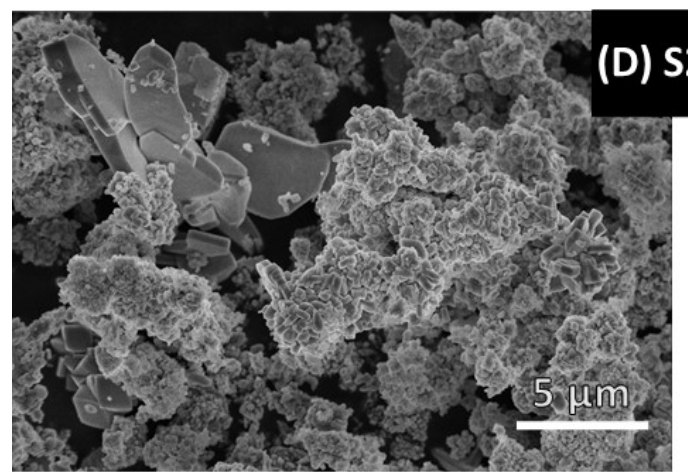

D) S200F

Figure 8. Cont. 

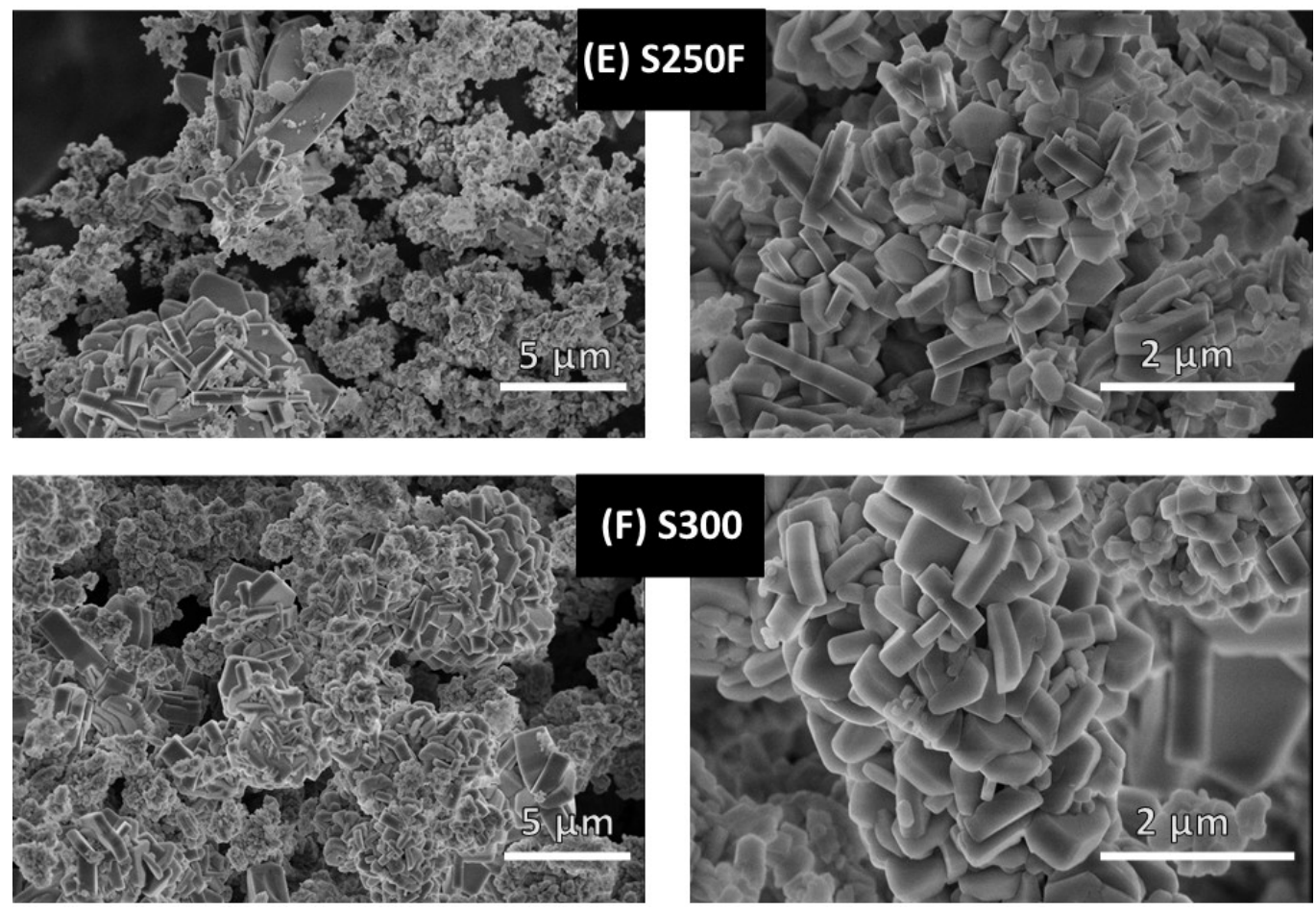

Figure 8. SEM micrographs corresponding to the following experimental samples: (A) S50F, (B) S100F, (C) S150F, (D) S200F, (E) S250F, (F) S300.

Table 4. Structural parameters derived from the XRD patterns the synthesized $\mathrm{LiFePO}_{4}$ particles and $\mathrm{Fe}_{3} \mathrm{O}_{4}$ impurity content.

\begin{tabular}{|c|c|c|c|c|c|c|c|}
\hline Samples & Planes & $\begin{array}{l}\text { Peak } \\
{ }^{\circ}(2 \theta)\end{array}$ & FWHM & $\begin{array}{l}\text { Crystallite } \\
\text { Size }^{*}(\mathrm{~nm})\end{array}$ & $\begin{array}{c}\text { Average } \\
\text { Crystallite } \\
\text { Size }^{*}(\mathrm{~nm})\end{array}$ & $\begin{array}{c}\mathrm{LiFePO}_{4} \\
(\%)\end{array}$ & $\begin{array}{c}\mathrm{Fe}_{3} \mathrm{O}_{4} \\
(\%)\end{array}$ \\
\hline \multirow{3}{*}{$\begin{array}{c}\text { Base } \\
\mathrm{LiFePO}_{4}\end{array}$} & $(101)$ & 20.643 & 0.110 & 109 & \multirow{3}{*}{82.5} & \multirow{3}{*}{99.74} & \multirow{3}{*}{0.26} \\
\hline & $(301)$ & 32.506 & 0.136 & 73.5 & & & \\
\hline & (311) & 35.443 & 0.144 & 65.0 & & & \\
\hline \multirow{3}{*}{ S100F } & $(101)$ & 20.949 & 0.195 & 45.4 & \multirow{3}{*}{34.26} & \multirow{3}{*}{82.11} & \multirow{3}{*}{17.89} \\
\hline & (301) & 29.715 & 0.320 & 26.5 & & & \\
\hline & (311) & 35.539 & 0.278 & 30.9 & & & \\
\hline \multirow{3}{*}{ S150F } & $(101)$ & 20.685 & 0.120 & 88.2 & \multirow{3}{*}{66.63} & \multirow{3}{*}{96.96} & \multirow{3}{*}{3.04} \\
\hline & (301) & 32.133 & 0.162 & 57.5 & & & \\
\hline & $(311)$ & 35.515 & 0.168 & 54.2 & & & \\
\hline \multirow{3}{*}{ S200F } & $(101)$ & 20.860 & 0.173 & 52.0 & \multirow{3}{*}{39.23} & \multirow{3}{*}{97.19} & \multirow{3}{*}{2.81} \\
\hline & $(301)$ & 32.292 & 0.257 & 33.2 & & & \\
\hline & $(311)$ & 35.681 & 0.265 & 32.5 & & & \\
\hline
\end{tabular}

* Parameter calculated considering the instrumental broadening.

In addition, the XRD patterns were fitted following the Rietveld method and the orthorhombic space group Pnma. Thus, the amount of magnetite impurities in the S100F, S150F and S200F samples (17.89\%, 3.04\%, and 2.81\% of $\mathrm{Fe}_{3} \mathrm{O}_{4}$, respectively) were quantified and compared against that of the base $\mathrm{LiFePO}_{4}$ sample $\left(0.26 \%\right.$ of $\left.\mathrm{Fe}_{3} \mathrm{O}_{4}\right)$.

Thereby, the values obtained for the samples studied confirmed the abrupt change presented by the interface of the S100F and S150F samples with regard to magnetite impurity and crystallinity, which made clear that the process requires the use of a reducing agent.

It can be, therefore, be considered that the heating rate within the $130-150{ }^{\circ} \mathrm{C}$ temperature range represents a crucial factor if highly crystalline and pure particles are to be 
obtained while using a smaller amount of reducing agents so that process costs can be kept under control.

\subsubsection{Growth Orientation and Morphology of the $\mathrm{LiFePO}_{4}$ Particles}

In order to investigate the effect from different heating configurations on the morphology and size of the $\mathrm{LiFePO}_{4}$ particles, all the samples were subjected to SEM analysis (see Figure 8).

In Figure 8A,B show that the reaction mediums that had not been slowly heated to a temperature of at least $130{ }^{\circ} \mathrm{C}$ generated products with widely varied morphology, where particles with fewer edges stand out (S50F, S100F). However, the samples that had been slowly heated over $130^{\circ} \mathrm{C}$ (pictures $\mathrm{C}-\mathrm{F}$ ) presented a clear morphology mostly formed by hexagonal microparticles (S150F, S200F, S250F, and S300). In order to contrast and clearly demonstrate the crystals generated with a greater number of facets on the samples showed in Figure 8C-F, the five high peaks corresponding to the planes were selected as follows:

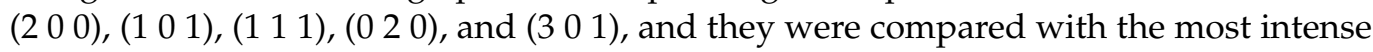
peak corresponding to the (3 11 ) plane (Table 5).

Table 5. Relative intensity ratios of the diffraction peaks in the XRD patterns of the synthesized $\mathrm{LiFePO}_{4}$.

\begin{tabular}{cccccccc}
\hline Intensity Ratios & F300 & S50F & S100F & S150F & S200F & S250F & S300 \\
\hline I (200)/(311) & 0.31 & 0.38 & 0.22 & 0.42 & 0.37 & 0.69 & 0.84 \\
$\mathrm{I}(101) /(311)$ & 0.64 & 0.59 & 0.47 & 0.79 & 0.76 & 0.64 & 0.56 \\
$\mathrm{I}(111) /(311)$ & 0.82 & 0.78 & 0.81 & 1.01 & 1.06 & 0.64 & 0.56 \\
$\mathrm{I}(020) /(311)$ & 0.63 & 0.70 & 0.71 & 0.78 & 0.77 & 0.85 & 0.70 \\
$\mathrm{I}(301) /(311)$ & 0.40 & 0.41 & 0.44 & 0.40 & 0.38 & 0.43 & 0.36 \\
\hline
\end{tabular}

The intensity ratios confirm the increasing trend that appears when the samples are generated by slow heating up to over $130^{\circ} \mathrm{C}$, by which the particles form a greater number of faces. It has, therefore, be demonstrated how the supersaturation of $\mathrm{Fe}^{+2}$ in the medium has a remarkable impact.

It should also be noted that that the hexagonal particles in sample S150F (see Figure 8) are evidently thinner, i.e., they have a shorter channel length [10] (see Figure 9). Given that Ceder et al. [44], had already demonstrated that lithium-ion diffusion is several orders of magnitude greater in the [10] direction than in the [1] and [101] directions, and also that $\mathrm{M}$. Saiful Islam et al. [45] proved through simulations, that the energy of Li-ion migration was lower in the [10] direction than in the [1] and [101] directions (Emig [10] $=0.55 \mathrm{eV}$, Emig [1] $=2.89 \mathrm{eV}$, and Emig [101] $=3.36 \mathrm{eV}$ ), we can affirm that the channel length [10] is a crucial factor to determine particle functionality. The increment in length that experiments the main diffusion channel of lithium ions as the slow heating time is increased (S200F, S250F and S300) may be due to the growth pattern followed by these particles (dissolutioncrystallization by Ostwald Ripening, OR) [38]. Even though the particles grow at a greater extent in other directions rather than in the [10] direction of the channel, it is a fact that they also grow in this direction over time. It should also be highlighted how as the heating time increases, size variations are also reduced. This has been corroborated by the results obtained from the different heating configurations applied in the experiments. For example, the particles in sample S150F (as can be seen in Table 3) are formed for 5.5 min under slow heating conditions, and later on, for another $3 \mathrm{~min}$, more particles are formed under fast heating conditions. This difference is less pronounced for example in the S300 sample. 


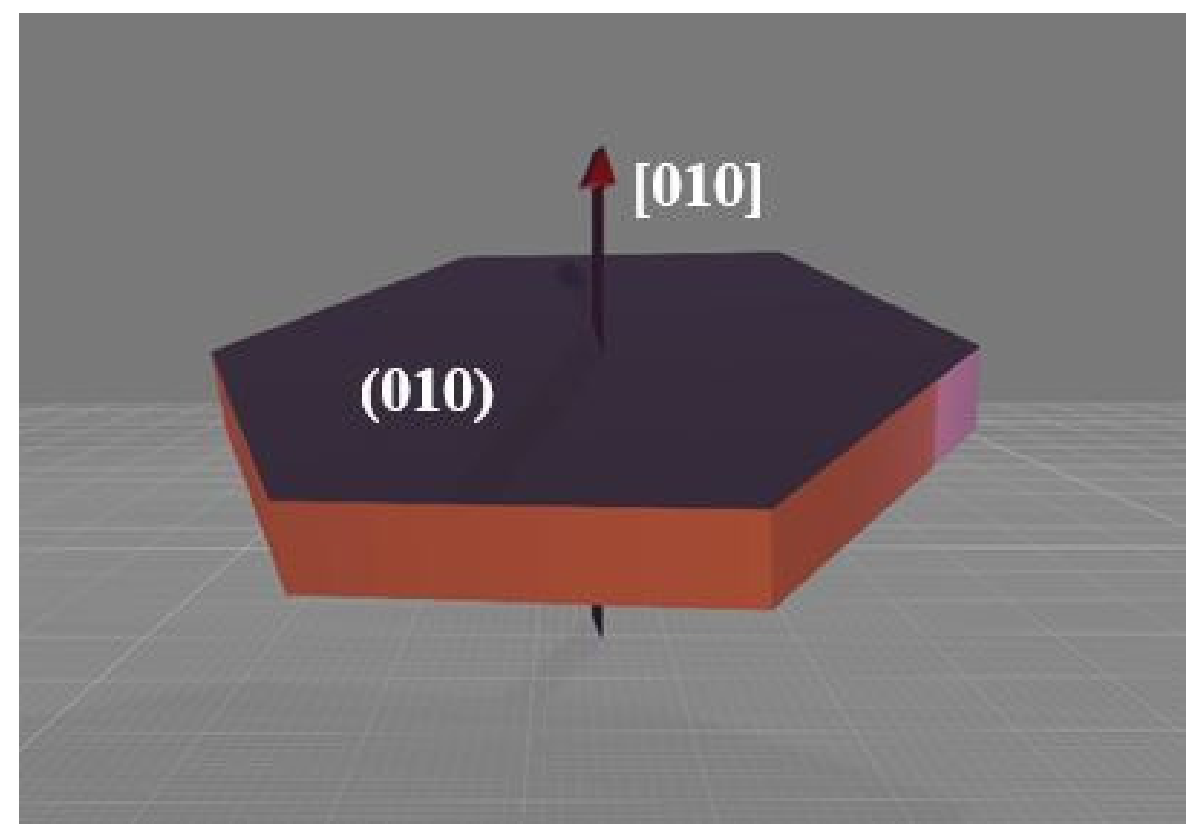

Figure 9. Direction of the particles' channel [010].

Therefore, it has been demonstrated that heating is a really essential factor at the same level as $\mathrm{pH}$ or lithium concentration regarding the generation of an optimal morphology, just as K. Dokko et al. [46], had already reported.

\section{Conclusions}

Our study has demonstrated that the configuration of the heating procedure poses a significant impact on the hydrothermal synthesis of $\mathrm{LiFePO}_{4}$ microparticles. Thus, the optimal values to be applied to such heating procedure in order to achieve the desired balance between particle quality and industrial viability could be deemed as the main innovative contribution by our study.

Industrial processes generally aim at the rapid production of particles, so that both resources and operating costs can be reduced. According to the results obtained from the present study, when high heating rates are implemented (F300 samples), the resulting particles present widely varying morphology, poor crystallinity, and considerable amounts of magnetite impurities. On the contrary, the particles that were generated through slow heating exhibited the opposite characteristics, i.e., consistent morphology, good crystallinity, and lower magnetite content, even if their industrial production could present some difficulties associated with the long times that would be required to form the particles (67.5 $\mathrm{min}$ in the case of S300 samples).

It has also been confirmed that an abrupt change can be observed in the S100F and S150F samples interfaces, with quite significant variations in their crystallinity as well as in magnetite impurities content $(17.89 \%$ and $3.04 \%$, respectively). This fact has allowed the separation of the samples into two groups as follows: firstly, the F300, S50F and S100F samples, with low crystalline particles and extremely high magnetite peaks; and secondly the S150F, S200F, S250F, and S300 samples, containing highly crystalline particles and presenting low or no magnetite peaks. Therefore, it has been verified that the samples that were subjected to slow heating rates above the minimum $\mathrm{LiFePO}_{4}$ particle formation temperature $\left(130{ }^{\circ} \mathrm{C}\right)$ notably improved their crystallinity and reduced their magnetite content, with sample S150F presenting an optimum crystallinity and morphology.

It can generally be concluded that for the formation of large amounts of $\mathrm{LiFePO}_{4}$ particles with good crystallinity levels, it is essential to implement low heating rates within the $130-150{ }^{\circ} \mathrm{C}$ temperature range. This would reduce the solubilisation of $\mathrm{Fe}_{3}\left(\mathrm{PO}_{4}\right)_{2} \cdot 8 \mathrm{H}_{2} \mathrm{O}$ that starts off within that temperature range and causes the medium $\mathrm{Fe}^{+2}$ supersaturation 
and its subsequent oxidization, which in turn results in a poorer crystallization of the $\mathrm{LiFePO}_{4}$ particles. Nevertheless, rather long operating times are still required and the use of reducing agents, even if at lesser amounts, would be highly recommended.

In order to reduce operating times and improve industrial viability, the following procedure should be used: extremely fast heating from room temperature to $130^{\circ} \mathrm{C}$, low heating rate from $130{ }^{\circ} \mathrm{C}$ to $150{ }^{\circ} \mathrm{C}$, and a final fast heating rate period until the desired final temperature is reached. Thanks to the actual capacity of the current industrial means to implement this fast heating rate in just a few seconds, this procedure should allow the production of optimally crystallized and rather size-consistent particles in just a few minutes. In addition, this process time could be further reduced by adding organic acids to the hydrothermal synthesis, such as J. Ni et al. [47] have already demonstrated.

In an attempt to summarize and clearly display the conclusions reached by this study, the effects from the varying parameters that have been analyzed are presented in Table 6 .

Table 6. Summary of effects from the varying parameters considered in this study on the following particle characteristics: purity, crystallinity, morphology, and size.

\begin{tabular}{|c|c|c|c|c|}
\hline Samples & & rity and Crystallinity & Morphology and Size & $\begin{array}{c}\text { Synthesis Process } \\
\text { Time * }(\mathrm{min})\end{array}$ \\
\hline F300 & $\begin{array}{l}\rightarrow \\
\rightarrow\end{array}$ & $\begin{array}{l}\text { Low crystallinity } \\
\text { Formation of } \\
\text { impurities }\end{array}$ & $\begin{array}{l}\text { Widely variable } \\
\text { morphology }\end{array}$ & 8.5 \\
\hline S50F & & $\begin{array}{l}\text { Low crystallinity } \\
\text { Formation of } \\
\text { impurities }\end{array}$ & $\begin{array}{l}\text { Widely variable } \\
\text { morphology }\end{array}$ & 12 \\
\hline S100F & & $\begin{array}{l}\text { Low crystallinity } \\
\text { Formation of } \\
\text { impurities }\end{array}$ & $\begin{array}{l}\text { Widely variable } \\
\text { morphology }\end{array}$ & 17.5 \\
\hline S150F & & $\begin{array}{l}\text { Extremely high } \\
\text { crystallinity } \\
\text { Reduced impurity } \\
\text { formation }\end{array}$ & $\begin{aligned} & \rightarrow \quad \begin{array}{l}\text { Hexagonal based } \\
\text { particles }\end{array} \\
& \rightarrow \quad \text { Shorter lithium-ion } \\
& \text { diffusion channel. } \\
& \rightarrow \quad \text { Larger particle size } \\
& \text { distribution }\end{aligned}$ & 26 \\
\hline S200F & & $\begin{array}{l}\text { Good crystallinity } \\
\text { Reduced impurity } \\
\text { formation }\end{array}$ & $\begin{array}{ll}\rightarrow \quad & \text { Hexagonal based } \\
& \text { particles } \\
\rightarrow \quad & \text { Longer lithium-ion } \\
& \text { diffusion channel. } \\
\rightarrow \quad & \text { Decreased particle } \\
\text { size distribution }\end{array}$ & 38 \\
\hline S250F & & $\begin{array}{l}\text { Good crystallinity } \\
\text { High purity }\end{array}$ & $\begin{array}{ll}\rightarrow \quad & \text { Hexagonal based } \\
& \text { particles } \\
\rightarrow \quad & \text { Longer lithium-ion } \\
& \text { diffusion channel. } \\
\rightarrow \quad & \text { Decreased particle } \\
& \text { size distribution }\end{array}$ & 52 \\
\hline S300 & $\begin{array}{l}\rightarrow \\
\rightarrow\end{array}$ & $\begin{array}{l}\text { Good crystallinity } \\
\text { High purity }\end{array}$ & $\begin{array}{ll}\rightarrow \quad & \text { Hexagonal based } \\
& \text { particles } \\
\rightarrow \quad & \text { Longer lithium-ion } \\
& \text { diffusion channel. } \\
\rightarrow \quad & \text { Decreased particle } \\
& \text { size distribution }\end{array}$ & 67.5 \\
\hline
\end{tabular}

* Synthesis process time: including slow heating + fast heating + reaction time. 
Author Contributions: Conceptualization, F.R.-J., A.B., M.B.G.-J., J.S.-O., J.R.P. and E.J.M.d.1.O.; methodology, F.R.-J.; software, F.R.-J. and A.B.; validation, F.R.-J., A.B., M.B.G.-J., J.S.-O., J.R.P. and E.J.M.d.1.O.; formal analysis, F.R.-J. and A.B.; investigation, F.R.-J. and A.B.; resources, F F.R.-J., A.B., M.B.G.-J., J.S.-O., J.R.P. and E E.J.M.d.l.O.; data curation, F.R.-J. and A.B.; writing original draft preparation, F.R.-J.; writing review and editing, A.B., M.B.G.-J., J.S.-O., J.R.P. and E.J.M.d.1.O.; visualization, F F.R.-J.; su-pervision, M.B.G.-J., J.S.-O., J.R.P. and E.J.M.d.l.O.; project administration, M.B.G.-J., J.S.-O., J.R.P. and E.J.M.d.I.O.; funding acquisition, M.B.G.-J., J.S.-O., J.R.P. and E.J.M.d.1.O. All authors have read and agreed to the published version of the manuscript.

Funding: This research received no external funding.

Acknowledgments: A. Benitez thanks the financial support from the European Social Fund and Junta de Andalucia. Finally, the authors wish to acknowledge the technical staff from the University Institute of Nanochemistry (IUNAN) of the University of Cordoba.

Conflicts of Interest: The authors declare no conflict of interest.

\section{References}

1. Yu, F.; Zhang, L.; Li, Y.; An, Y.; Zhu, M.; Dai, B. Mechanism studies of $\mathrm{LiFePO}_{4}$ cathode material: Lithiation/delithiation process, electrochemical modification and synthetic reaction. RSC Adv. 2014, 4, 54576-54602. [CrossRef]

2. Panda, P.K.; Grigoriev, A.; Mishra, Y.K.; Ahuja, R. Progress in supercapacitors: Roles of two dimensional nanotubular materials. Nanoscale Adv. 2020, 2, 70-108. [CrossRef]

3. Benítez, A.; Morales, J.; Caballero, Á. Pistachio shell-derived carbon activated with phosphoric acid: A more efficient procedure to improve the performance of li-s batteries. Nanomaterials 2020, 10, 840. [CrossRef]

4. Xin, S.; Yin, Y.X.; Guo, Y.G.; Wan, L.J. A high-energy room-temperature sodium-sulfur battery. Adv. Mater. 2014, 26, 1261-1265. [CrossRef]

5. Perry, M.L.; Weber, A.Z. Advanced Redox-Flow Batteries: A Perspective. J. Electrochem. Soc. 2016, 163, A5064-A5067. [CrossRef]

6. Zhang, B.; Wang, S.; Li, Y.; Sun, P.; Yang, C.; Wang, D.; Liu, L. Review: Phase transition mechanism and supercritical hydrothermal synthesis of nano lithium iron phosphate. Ceram. Int. 2020, 46, 27922-27939. [CrossRef]

7. Satyavani, T.V.S.L.; Srinivas Kumar, A.; Subba Rao, P.S.V. Methods of synthesis and performance improvement of lithium iron phosphate for high rate Li-ion batteries: A review. Eng. Sci. Technol. Int. J. 2016, 19, 178-188. [CrossRef]

8. Dong, Y.Z.; Zhao, Y.M.; Chen, Y.H.; He, Z.F.; Kuang, Q. Optimized carbon-coated $\mathrm{LiFePO}_{4}$ cathode material for lithium-ion batteries. Mater. Chem. Phys. 2009, 115, 245-250. [CrossRef]

9. Chen, Z.; Zhu, H.; Ji, S.; Fakir, R.; Linkov, V. Influence of carbon sources on electrochemical performances of $\mathrm{LiFePO}_{4} / \mathrm{C}$ composites. Solid State Ionics 2008, 179, 1810-1815. [CrossRef]

10. Franger, S.; Le Cras, F.; Bourbon, C.; Rouault, H. Comparison between different $\mathrm{LiFePO}_{4}$ synthesis routes and their influence on its physico-chemical properties. J. Power Sources 2003, 119-121, 252-257. [CrossRef]

11. Kosova, N.; Devyatkina, E. On mechanochemical preparation of materials with enhanced characteristics for lithium batteries. Solid State Ionics 2004, 172, 181-184. [CrossRef]

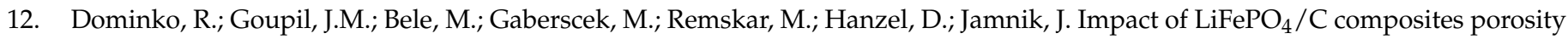
on their electrochemical performance. J. Electrochem. Soc. 2005, 152, A858. [CrossRef]

13. Park, K.S.; Son, J.T.; Chung, H.T.; Kim, S.J.; Lee, C.H.; Kim, H.G. Synthesis of $\mathrm{LiFePO}_{4}$ by co-precipitation and microwave heating. Electrochem. Commun. 2003, 5, 839-842. [CrossRef]

14. Arnold, G.; Garche, J.; Hemmer, R.; Ströbele, S.; Vogler, C.; Wohlfahrt-Mehrens, M. Fine-particle lithium iron phosphate LiFePO 4 synthesized by a new low-cost aqueous precipitation technique. J. Power Sources 2003, 119-121, 247-251. [CrossRef]

15. Benedek, P.; Wenzler, N.; Yarema, M.; Wood, V.C. Low temperature hydrothermal synthesis of battery grade lithium iron phosphate. RSC Adv. 2017, 7, 17763-17767. [CrossRef]

16. Lee, J.; Teja, A.S. Characteristics of lithium iron phosphate $\left(\mathrm{LiFePO}_{4}\right)$ particles synthesized in subcritical and supercritical water. J. Supercrit. Fluids 2005, 35, 83-90. [CrossRef]

17. Xu, C.; Lee, J.; Teja, A.S. Continuous hydrothermal synthesis of lithium iron phosphate particles in subcritical and supercritical water. J. Supercrit. Fluids 2008, 44, 92-97. [CrossRef]

18. Jin, E.M.; Jin, B.; Jun, D.K.; Park, K.H.; Gu, H.B.; Kim, K.W. A study on the electrochemical characteristics of $\mathrm{LiFePO}_{4}$ cathode for lithium polymer batteries by hydrothermal method. J. Power Sources 2008, 178, 801-806. [CrossRef]

19. Gu, Y.J.; Li, C.J.; Cheng, L.; Lv, P.G.; Fu, F.J.; Liu, H.Q.; Ding, J.X.; Wang, Y.M.; Chen, Y.B.; Wang, H.F.; et al. Novel synthesis of plate-like $\mathrm{LiFePO}_{4}$ by hydrothermal method. J. New Mater. Electrochem. Syst. 2016, 19, 33-36. [CrossRef]

20. He, L.H.; Zhao, Z.W.; Liu, X.H.; Chen, A.L.; Si, X.F. Thermodynamics analysis of $\mathrm{LiFePO}_{4}$ pecipitation from Li-Fe(II)-P-H $2 \mathrm{O}$ system at 298 K. Trans. Nonferrous Met. Soc. China 2012, 22, 1766-1770. [CrossRef]

21. Paolella, A.; Bertoni, G.; Hovington, P.; Feng, Z.; Flacau, R.; Prato, M.; Colombo, M.; Marras, S.; Manna, L.; Turner, S.; et al. Cation exchange mediated elimination of the Fe-antisites in the hydrothermal synthesis of $\mathrm{LiFePO}_{4}$. Nano Energy 2015, 16, 256-267. [CrossRef] 
22. Vediappan, K.; Guerfi, A.; Gariépy, V.; Demopoulos, G.P.; Hovington, P.; Trottier, J.; Mauger, A.; Julien, C.M.; Zaghib, K. Stirring effect in hydrothermal synthesis of nano C-LiFePO 4 . J. Power Sources 2014, 266, 99-106. [CrossRef]

23. Wu, G.; Liu, N.; Gao, X.; Tian, X.; Zhu, Y.; Zhou, Y.; Zhu, Q. A hydrothermally synthesized LiFePO 4 /C composite with superior low-temperature performance and cycle life. Appl. Surf. Sci. 2018, 435, 1329-1336. [CrossRef]

24. Liu, Y.; Gu, J.; Zhang, J.; Yu, F.; Wang, J.; Nie, N.; Li, W. LiFePO 4 nanoparticles growth with preferential (010) face modulated by Tween-80. RSC Adv. 2015, 5, 9745-9751. [CrossRef]

25. Liang, Y.P.; Li, C.C.; Chen, W.J.; Lee, J.T. Hydrothermal synthesis of lithium iron phosphate using pyrrole as an efficient reducing agent. Electrochim. Acta 2013, 87, 763-769. [CrossRef]

26. Gunawan, I.; Wagiyo, H. Synthesis of $\mathrm{LiFePO}_{4}$ in the Presence of Organic Reductant by Hydrothermal Method and its Characterization. Macromol. Symp. 2015, 353, 225-230. [CrossRef]

27. Golestani, E.; Javanbakht, M.; Ghafarian-Zahmatkesh, H.; Beydaghi, H.; Ghaemi, M. Tartaric acid assisted carbonization of $\mathrm{LiFePO}_{4}$ synthesized through in situ hydrothermal process in aqueous glycerol solution. Electrochim. Acta 2018, $259,903-915$. [CrossRef]

28. Qin, X.; Wang, J.; Xie, J.; Li, F.; Wen, L.; Wang, X. Hydrothermally synthesized $\mathrm{LiFePO}_{4}$ crystals with enhanced electrochemical properties: Simultaneous suppression of crystal growth along [10] and antisite defect formation. Phys. Chem. Chem. Phys. 2012, 14, 2669-2677. [CrossRef]

29. Johnson, I.D.; Lübke, M.; Wu, O.Y.; Makwana, N.M.; Smales, G.J.; Islam, H.U.; Dedigama, R.Y.; Gruar, R.I.; Tighe, C.J.; Scanlon, D.O.; et al. Pilot-scale continuous synthesis of a vanadium-doped $\mathrm{LiFePO}_{4} / \mathrm{C}$ nanocomposite high-rate cathodes for lithium-ion batteries. J. Power Sources 2016, 302, 410-418. [CrossRef]

30. Paolella, A.; Turner, S.; Bertoni, G.; Hovington, P.; Flacau, R.; Boyer, C.; Feng, Z.; Colombo, M.; Marras, S.; Prato, M.; et al. Accelerated Removal of Fe-Antisite Defects while Nanosizing Hydrothermal $\mathrm{LiFePO}_{4}$ with Ca ${ }^{2+}$. Nano Lett. 2016, 16, $2692-2697$. [CrossRef]

31. Yen, H.; Rohan, R.; Chiou, C.Y.; Hsieh, C.J.; Bolloju, S.; Li, C.C.; Yang, Y.F.; Ong, C.W.; Lee, J.T. Hierarchy concomitant in situ stable iron(II)-carbon source manipulation using ferrocenecarboxylic acid for hydrothermal synthesis of $\mathrm{LiFePO}_{4}$ as high-capacity battery cathode. Electrochim. Acta 2017, 253, 227-238. [CrossRef]

32. Kim, J.K. Supercritical synthesis in combination with a spray process for 3D porous microsphere lithium iron phosphate. CrystEngComm 2014, 16, 2818-2822. [CrossRef]

33. Hong, S.A.; Kim, S.J.; Chung, K.Y.; Chun, M.S.; Lee, B.G.; Kim, J. Continuous synthesis of lithium iron phosphate $\left(\mathrm{LiFePO}_{4}\right)$ nanoparticles in supercritical water: Effect of mixing tee. J. Supercrit. Fluids 2013, 73, 70-79. [CrossRef]

34. Ruiz-Jorge, F.; Benítez, A.; Fernández-García, S.; Sánchez-Oneto, J.; Portela, J.R. Effect of Fast Heating and Cooling in the Hydrothermal Synthesis on $\mathrm{LiFePO}_{4}$ Microparticles. Ind. Eng. Chem. Res. 2020, 59, 9318-9327. [CrossRef]

35. Vasquez-Elizondo, L.J.; Rendón-Ángeles, J.C.; Matamoros-Veloza, Z.; López-Cuevas, J.; Yanagisawa, K. Urea decomposition enhancing the hydrothermal synthesis of lithium iron phosphate powders: Effect of the lithium precursor. Adv. Powder Technol. 2017, 28, 1593-1602. [CrossRef]

36. Chen, J.; Wang, S.; Whittingham, M.S. Hydrothermal synthesis of cathode materials. J. Power Sources 2007, 174, 442-448. [CrossRef]

37. Sánchez-Oneto, J.; Portela, J.R.; Nebot, E.; de la Ossa, E.M. Hydrothermal oxidation: Application to the treatment of different cutting fluid wastes. J. Hazard. Mater. 2007, 144, 639-644. [CrossRef] [PubMed]

38. Zhu, J.; Fiore, J.; Li, D.; Kinsinger, N.M.; Wang, Q.; DiMasi, E.; Guo, J.; Kisailus, D. Solvothermal synthesis, development, and performance of $\mathrm{LiFePO}_{4}$ nanostructures. Cryst. Growth Des. 2013, 13, 4659-4666. [CrossRef]

39. Gerhild, T.L. Schikorr Reaction: Iron(II) Hydroxide, Iron(II,III) Oxide; Betascript Publishing: Beau Bassin, Mauritius, 2012.

40. Min, C.; Ou, X.; Shi, Z.; Liang, G.; Wang, L. Effects of heating rate on morphology and performance of lithium iron phosphate synthesized by hydrothermal route in organic-free solution. Ionics 2017, 24, 1285-1292. [CrossRef]

41. Ellis, B.; Kan, W.H.; Makahnouk, W.R.M.; Nazar, L.F. Synthesis of nanocrystals and morphology control of hydrothermally prepared $\mathrm{LiFePO}_{4}$. J. Mater. Chem. 2007, 17, 3248-3254. [CrossRef]

42. Fisher, C.A.J.; Islam, M.S. Surface structures and crystal morphologies of $\mathrm{LiFePO}_{4}$ : Relevance to electrochemical behaviour. J. Mater. Chem. 2008, 18, 1209-1215. [CrossRef]

43. Amaro-Gahete, J.; Benítez, A.; Otero, R.; Esquivel, D.; Jiménez-Sanchidrián, C.; Morales, J.; Caballero, Á.; Romero-Salguero, F.J. A comparative study of particle size distribution of graphene nanosheets synthesized by an ultrasound-assisted method. Nanomaterials 2019, 9, 152. [CrossRef] [PubMed]

44. Morgan, D.; Van der Ven, A.; Ceder, G. Li Conductivity in $\mathrm{Li}_{\mathrm{x}} \mathrm{MPO}_{4}(\mathrm{M}=\mathrm{Mn}, \mathrm{Fe}, \mathrm{Co}, \mathrm{Ni})$ Olivine Materials. Electrochem. Solid-State Lett. 2004, 7, A30. [CrossRef]

45. Islam, M.S.; Driscoll, D.J.; Fisher, C.A.J.; Slater, P.R. Atomic-scale investigation of defects, dopants, and lithium transport in the $\mathrm{LiFePO}_{4}$ olivine-type battery material. Chem. Mater. 2005, 17, 5085-5092. [CrossRef]

46. Dokko, K.; Koizumi, S.; Nakano, H.; Kanamura, K. Particle morphology, crystal orientation, and electrochemical reactivity of $\mathrm{LiFePO}_{4}$ synthesized by the hydrothermal method at $443 \mathrm{~K}$. J. Mater. Chem. 2007, 17, 4803. [CrossRef]

47. Ni, J.; Morishita, M.; Kawabe, Y.; Watada, M.; Takeichi, N.; Sakai, T. Hydrothermal preparation of LiFePO 4 nanocrystals mediated by organic acid. J. Power Sources 2010, 195, 2877-2882. [CrossRef] 